\title{
Total Number and Ratio of GABAergic Neuron Types in the Mouse Lateral and Basal Amygdala
}

\author{
Viktória K. Vereczki, ${ }^{1,2 *}$ Kinga Müller, ${ }^{2,3 *}$ Éva Krizsán, ${ }^{2}$ Zoltán Máté, ${ }^{2}$ Zsuzsanna Fekete, ${ }^{2,3}$ \\ Laura Rovira-Esteban, ${ }^{2}$ Judit M. Veres, ${ }^{2}$ Ferenc Erdélyi, ${ }^{2}$ and Norbert Hájos ${ }^{2}$ \\ ${ }^{1}$ Department of Anatomy, Histology and Embryology, Faculty of Medicine, Semmelweis University, Budapest, 1094, Hungary, ${ }^{2}$ ELRN Institute of \\ Experimental Medicine, Budapest, 1083, Hungary, and ${ }^{3}$ János Szentágothai Doctoral School of Neuroscience, Semmelweis University, Budapest, \\ 1085, Hungary
}

GABAergic neurons are key circuit elements in cortical networks. Despite growing evidence showing that inhibitory cells play a critical role in the lateral (LA) and basal (BA) amygdala functions, neither the number of GABAergic neurons nor the ratio of their distinct types has been determined in these amygdalar nuclei. Using unbiased stereology, we found that the ratio of GABAergic neurons in the BA (22\%) is significantly higher than in the LA (16\%) in both male and female mice. No difference was observed between the right and left hemispheres in either sex. In addition, we assessed the ratio of the major inhibitory cell types in both amygdalar nuclei. Using transgenic mice and a viral strategy for visualizing inhibitory cells combined with immunocytochemistry, we estimated that the following cell types together compose the vast majority of GABAergic cells in the LA and BA: axo-axonic cells (5.5\%-6\%), basket cells expressing parvalbumin (17\%-20\%) or cholecystokinin (7\%-9\%), dendrite-targeting inhibitory cells expressing somatostatin (10\%-16\%), NPY-containing neurogliaform cells (14\%-15\%), VIP and/or calretinin-expressing interneuron-selective interneurons (29\%-38\%), and GABAergic projection neurons expressing somatostatin and neuronal nitric oxide synthase (5.5\%-8\%). Our results show that these amygdalar nuclei contain all major GABAergic neuron types as found in other cortical regions. Furthermore, our data offer an essential reference for future studies aiming to reveal changes in GABAergic cell number and in inhibitory cell types typically observed under different pathologic conditions, and to model functioning amygdalar networks in health and disease.

Key words: connectivity; emotion; inhibitory cells; interneuron; local circuits; neuropeptide

Significance Statement

GABAergic cells in cortical structures, as in the lateral and basal nucleus of the amygdala, have a determinant role in controlling circuit operation. In this study, we provide the first estimate for the total number of inhibitory cells in these two amygdalar nuclei. In addition, our study is the first to define the ratio of the major GABAergic cell types present in these cortical networks. Taking into account that hyperexcitability in the amygdala, arising from the imbalance between excitation and inhibition typifies many altered brain functions, including anxiety, post-traumatic stress disorder, schizophrenia, and autism, uncovering the number and ratio of distinct amygdalar inhibitory cell types offers a solid base for comparing the changes in inhibition in pathologic brain states.

Received Oct. 21, 2020; revised Mar. 14, 2021; accepted Mar. 28, 2021.

Author contributions: N.H., V.K.V., and F.E. designed research; N.H., V.K.V., K.M., E.K., Z.M., Z.F., L.R.-E., F.E., and J.M.V. analyzed data; N.H., V.K.V., K.M., Z.F., and L.R.-E. edited the paper; N.H. wrote the paper; V.K.V., K.M., E.K., Z.M., Z.F., and L.R.-E. performed research.

This work was supported by Semmelweis University Intramural Program to V.K.V., National Research, Development and Innovation Office K_ 119742 to N.H., Hungarian Brain Research Program 2017-1.2.1-NKP2017-00002 to N.H., and from Semmelweis University (EFOP-3.6.3-VEKOP-16-2017-00009) awarded to M.K. We thank Erzsébet Gregori for excellent technical assistance; and László Barna (Nikon Microscopy Center at the Institute of Experimental Medicine, Nikon Austria, and Auro-Science Consulting) for kindly providing microscopy support.

*V.K.V. and K.M. contributed equally to this work.

The authors declare no competing financial interests.

Correspondence should be addressed to Norbert Hájos at hajos@koki.hu.

https://doi.org/10.1523/JNEUROSCI.2700-20.2021

Copyright $\odot 2021$ the authors

\section{Introduction}

The amygdala is a complex structure that is composed of several functionally distinct nuclei. One of the main amygdalar regions, the basolateral amygdaloid complex (BLA), plays a key role in a variety of behavioral functions, including goal-directed and social behavior, formation and storage of affective memory as well as controlling the direction of attention (Phelps and LeDoux, 2005; Phelps et al., 2014; Janak and Tye, 2015; Gothard, 2020). The BLA, which is a nuclear extension of the cortex deep in the temporal lobe, consists of the lateral (LA), basal (BA) and accessory basal nuclei (Pitkanen et al., 1997). As in other cortical regions, the BLA principal cells giving rise to both local axonal collaterals and projections to remote target areas use glutamate 
for fast neurotransmission (Smith and Paré, 1994; McDonald, 1996; Paré and Smith, 1998; Pitkanen et al., 2003). In addition to these excitatory cells, there are neurons in the BLA that release GABA as the main neurotransmitter molecule (McDonald, 1985; McDonald and Augustine, 1993). Previous studies obtained in rat and monkey estimated the number of GABAergic cells to be $\sim 15 \%$ and $\sim 25 \%$ of the total neuronal population, respectively (McDonald, 1992; McDonald and Augustine, 1993). However, in these studies, only male animals were investigated at a given BLA level in one of the hemispheres without separating the distinct BLA nuclei. Thus, it is unexplored whether there are differences in the GABAergic cell number between the nuclei, sexes and/or hemispheres.

Cortical inhibitory neurons are remarkably heterogeneous in their morphologic, molecular, and functional features (Kepecs and Fishell, 2014; Pelkey et al., 2017; Huang and Paul, 2019). Previous studies have established several cardinal GABAergic cell types that can be ubiquitously identified in all cortical regions and can be characterized by typical neurochemical content or a combination of these markers (Kepecs and Fishell, 2014). Axo-axonic cells, either containing or lacking the calcium binding protein parvalbumin (PV), target specifically the axon initial segment of excitatory principal neurons (Somogyi, 1977; He et al., 2016). Two types of basket cells innervating predominantly the soma and spine-free proximal dendrites of neurons express either PV or a neuropeptide cholecystokinin (CCK) and cannabinoid receptor Type 1 (CB1) (Freund and Katona, 2007). Dendrite-targeting interneurons can be also separated into two types: one, containing somatostatin (SST), forms synaptic contacts predominantly with the distal dendrites of neurons (Kawaguchi and Kubota, 1996), whereas the other one, the so-called neurogliaform cell, often expressing neuropeptide Y (NPY), is responsible for slow inhibition of dendrites (Tamas et al., 2003). Another group of GABAergic cells is formed by interneuron-selective interneurons innervating specifically, if not exclusively, other GABAergic neurons and may contain vasoactive intestinal polypeptide (VIP) and/ or the calcium binding protein calretinin (CR) (Acsády et al., 1996; Gulyas et al., 1996). Finally, there are GABAergic neurons that, in addition to their local axonal collateralization, project to remote brain areas and often show immunoreactivity for SST and neuronal nitric oxide synthase (nNOS) (Gulyas et al., 2003; He et al., 2016). Both the number and the ratio of distinct GABAergic neuron types show substantial variability among cortical regions (Kim et al., 2017) that may have significant computational consequences (Harris and Shepherd, 2015). Therefore, these circuit parameters in amygdalar networks should be determined to better understand circuit operation in the BLA.

Our study has been conducted in the LA and BA, the two nuclei that play distinct roles in various amygdala functions (Janak and Tye, 2015; Manassero et al., 2018) and may differ in their inhibitory circuits (Polepalli et al., 2020). For unbiased stereology, we visualized the GABAergic neurons in the mouse brain by intercrossing vesicular GABA transporter (Vgat)-Cre transgenic mice with reporter mice. To determine the fractions of distinct types of GABAergic neurons, we combined labeling of genetically defined neuronal populations in transgenic mice with immunocytochemistry. These approaches allowed us to accurately estimate the number of GABAergic neurons and the ratio of their types in the LA and BA.

\section{Materials and Methods}

Animals. All procedures involving animals were performed according to methods approved by the Hungarian legislation (1998 XXVIII, section 243/1998, renewed in 40/2013) and institutional guidelines. All procedures were in compliance with the European convention for the protection of vertebrate animals used for experimental and other scientific purposes (ETS number 123). Every effort was taken to minimize animal suffering and the number of animals used. For this study, the following mouse lines were obtained from The Jackson Laboratory or from MMRRC (Table 1). To study CCK-expressing GABAergic neurons, Vgat-IRES-Cre mice were bred with BAC-CCK-GFPcoIN_sb mice and the offspring ( $\mathrm{Vgat}^{\mathrm{Cre}}$;CCK-GFPcoIN) were used in experiments. Two lines of BAC-CCK-GFPcoIN_sb mice differing in the BAC transgene copy number were generated similarly as BAC-CCK-DsRedT3 mice (Mate et al., 2013). In the offspring of the one copy line intercrossed with Vgat-IRES-Cre, GFP expression had lower levels compared with those offspring generated by crossing the two copy line with Vgat-IRESCre mice. Electrophysiological measurements were obtained in the offspring of BAC-CCK-GFPcoIN_sb mice having one or two copies of BAC transgene, whereas the interneuron counting was performed only in offspring of the two copy mouse line.

Males and females were used for stereology and electrophysiological recordings, whereas only the right hemisphere of the male mice was used to estimate the proportion of distinct interneuron types in each case. Mice were housed in same-sex groupings (2-4 per cage). Housing was in a temperature- and humidity-controlled vivarium under a $12 \mathrm{~h}$ light/dark cycle (lights on 06:00 h).

Stereological analysis. Brain tissue samples for stereological analyses were taken from 3 males and 3 females that were offspring of homozygous Vgat-IRES-Cre mice crossed with homozygous Ai6. After being anesthetized with ketamine/xylazine, adult mice (P56-P70) were transcardially perfused with $0.9 \% \mathrm{NaCl}$ for $1-2 \mathrm{~min}$ followed by a fixative solution containing $4 \% \mathrm{PFA}$ in $0.1 \mathrm{M} \mathrm{PB}, \mathrm{pH} 7.4$, for $20 \mathrm{~min}$. Coronal sections $(50 \mu \mathrm{m}$ thick) were prepared from the tissue blocks containing the entire amygdalar region using a Leica VT1000S vibratome (Leica Microsystems). Sections were stored in a cryoprotectant antifreeze solution consisting of glycerol, ethylene glycol, distilled $\mathrm{H}_{2} \mathrm{O}$, and PBS (3:3:3:1 volume ratio) at $-20^{\circ} \mathrm{C}$ until further processing (Watson et al., 1986). Using a random starting point within the amygdala, six or seven sections per animal containing the BLA were selected. The sections separated by $250 \mu \mathrm{m}$ in rostro-caudal extent were immunostained for a neuronal marker (NeuN) and for vesicular acetylcholine transporter (VAchT) (Table 1). The latter was used to define the borders of the BA. After several washing steps, the sections were mounted and coverslipped with Vectashield (Vector Laboratories). Multichannel confocal images of the LA and BA were obtained using a Nikon A1R microscope, apochromatic lens (CFI Plan Apo VC20x NA 0.75) ( $z$ stacks, $1 \mu \mathrm{m}$ step size). Quantitative analyses were performed on a computer-assisted image analysis system consisting of a MBF MS-88 computer-controlled motorized stage, an MBF DV-47d video camera, a Windows 7 PC computer, and StereoInvestigator program (MicroBrightField), a custom-designed morphology, and stereology software. Tracings were made from the ventral through the dorsal extent of the amygdala. A total of six or seven tracings were made per amygdala, per hemisphere in each animal on both sides. After outlining the boundary of the LA and BA for each section at a low magnification, the software placed a set of optical dissector frames $(50 \times 50 \mu \mathrm{m})$ within each boundary in a systematic-random fashion where sampling grid was in the amygdala (grid size, $75 \times 85 \mu \mathrm{m}$ in the LA and $75 \times 130 \mu \mathrm{m}$ in the BA). Neurons were then counted in depth of $9 \mu \mathrm{m}$, according to stereological principles (West et al., 1991). In each amygdala, at least 500 neurons were sampled to ensure robustness of the data (Schmitz and Hof, 2000). Only $\mathrm{NeuN}^{+}$cells were counted. We have noticed that some ZsGreen1-expressing cells with small soma (2\%-6\% of all ZsGreen1-labeled cells) lacked NeuN staining, and therefore were excluded from the counting. In addition, dense islands composed of 5-20 ZsGreen1-expressing small $\mathrm{NeuN}^{+}$neurons were also excluded from the counting, as these neurons belong to the intercalated cell mass (see images taken at -1.85 and $-2.1 \mathrm{~mm}$ to bregma in Fig. 1A).

To determine the completeness and specificity of labeling in offspring generated by crossing Vgat-Cre with Ai6 mice, we immunostained sections with a cocktail of antibodies with an aim to visualize all 
Table 1. To estimate the total number of GABAergic neurons and the ratio of distinct inhibitory cell types in the LA and BA, the mouse lines, AAVs, and combinations of antibodies to visualize the given antigens used in this study

\begin{tabular}{|c|c|c|}
\hline Cell types & Mouse lines & Mixture of primary and secondary antibodies \\
\hline GABAergic neurons & $\begin{array}{l}\text { Vgat-IRES-Cre (Slc32a1tm2(cre)Lowl, JAX stock \#028862) x } \\
\text { Ai6 reporter (Gt(ROSA)26Sor_tm6(CAG/ } \\
\text { LSL_ZsGreen1)Hze) }\end{array}$ & $\begin{array}{l}\text { Chicken anti-NeuN, rabbit anti-VAChT } \\
\text { Cy3-conjugated anti-chicken, A647-conjugated anti-rabbit } \\
\text { OR } \\
\text { Chicken anti-NeuN, rabbit anti-PV, rabbit anti-CB, rabbit anti-proCCK, rabbit anti-VIP, rabbit } \\
\text { anti-CR, rabbit anti-SST, rabbit anti-NPY, goat anti-nNOS } \\
\text { DyL405-conjugated anti-chicken, Cy3-conjugated anti-rabbit, Cy3-conjugated anti-goat }\end{array}$ \\
\hline $\mathrm{PV}^{+}$interneurons & $\begin{array}{l}\text { Pvalb-IRES-Cre (Pvalbtm1(cre)Arbr, JAX stock \#008069) } \\
+ \text { AAV5-DI0-EYFP }\end{array}$ & $\begin{array}{l}\text { Chicken anti-NeuN, goat anti-GFP, guinea pig anti-CB } \\
\text { DyL405-conjugated anti-chicken, A488-conjugated anti-goat, Cy3-conjugated anti-guinea pig }\end{array}$ \\
\hline $\mathrm{CCK}^{+}$GABAergic neurons & $\begin{array}{l}\text { Vgat }^{\mathrm{Cre}} ; \text {;CCK-GFPcolN } \\
\text { offspring of BAC-CCK-GFPcolN_sb x Vgat-IRES-Cre }\end{array}$ & $\begin{array}{l}\text { Chicken anti-NeuN, goat anti-GFP, rabbit anti-proCCK } \\
\text { DyL405-conjugated anti-chicken, A488-conjugated anti-goat, Cy3-conjugated anti-rabbit }\end{array}$ \\
\hline $\mathrm{CCK}^{+} / \mathrm{VIP}^{+}$interneurons & $\begin{array}{l}\text { Vip }{ }^{\text {Cre }} \text {;CCK-GFPcoIN } \\
\text { offspring of BAC-CCK-GFPcolN_sb x Vip-IRES-Cre (VIPtm1(cre) } \\
\quad \text { Zjh, JAX stock \#010908) }\end{array}$ & $\begin{array}{l}\text { Mouse anti-GFP, rabbit anti-proCCK } \\
\text { A488-conjugated anti-mouse, Cy3-conjugated anti-rabbit } \\
\text { OR } \\
\text { Mouse anti-GFP, rabbit anti-VIP } \\
\text { A488-conjugated anti-mouse, Cy3-conjugated anti-rabbit }\end{array}$ \\
\hline $\begin{array}{l}\text { Interneuron-selective } \\
\text { interneurons }\end{array}$ & $\begin{array}{l}\text { Vip-IRES-Cre } \\
+ \text { AAV5-DI0-EYFP }\end{array}$ & $\begin{array}{l}\text { Chicken anti-NeuN, goat anti-GFP, guinea pig anti-CR } \\
\text { DyL405-conjugated anti-chicken, A488-conjugated anti-goat, Cy3-conjugated anti-guinea pig }\end{array}$ \\
\hline
\end{tabular}

$\mathrm{SST}^{+}$GABAergic neurons Sst-IRES-Cre (Ssttm2.1(cre)Zjh, Jax stock \#013044)

sampled in acute slices + AAV5-DI0-EYFP

OR

AAVretro-mCherry-Flpo and

AAVdj-Con/Fon-EYFP

$\mathrm{SST}^{+}$GABAergic neurons Sst-IRES-Cre

+ AAV5-DI0-EYFP

$\mathrm{SST}^{+}$GABAergic neurons Vgat-IRES-Cre $\mathrm{x}$

expressing PV Ai6 reporter

$\mathrm{NPY}^{+}$neurons sampled BAC-Npy-Cre mice (strain \# RRID:MMRRC_034810-UCD) x

in acute slices Ai14 reporter (Gt(ROSA)26Sor_tm14(CAG/

LSL_tdTomato)Hze)

$\mathrm{NPY}^{+}$GABAergic neurons $\mathrm{Npy}^{\mathrm{C} \text { (re }} ; \mathrm{Dl} \times 5 / 6^{\mathrm{Flp}}$

offspring of BAC-Npy-Cre mice $x$

Dlx5/6-Flpe (Tg(ml56i-flpe)39Fsh, JAX stock \#010815)

+ AAVdj-Con/Fon-EYFP

Chicken anti-NeuN, mouse anti-GFP, goat anti-nNOS

DyL405-conjugated anti-chicken, A488-conjugated anti-mouse, Cy3-conjugated anti-goat Rabbit anti-PV, rat anti-SST

DyL405-conjugated anti-rabbit, Cy3-conjugated anti-rat

Chicken anti-NeuN, mouse anti-GFP, goat anti-PV, rabbit anti-SST

DyL405-conjugated anti-chicken, A488-conjugated anti-mouse, Cy3-conjugated anti-goat, A647-conjugated anti-rabbit

OR

Chicken anti-NeuN, mouse anti-GFP, rabbit anti-PV, rabbit anti-SST, rabbit anti-CB

DyL405-conjugated anti-chicken, A488-conjugated anti-mouse, Cy3-conjugated anti-rabbit the major inhibitory cell types (Table 1 ). Our counting revealed that ZsGreen1 was present in almost all GABAergic neurons identified with immunostaining (99.1\%, $n=1291, n=2$ mice), indicating that all known inhibitory cells are readily visualized in offspring. Then we counted how many ZsGreen1-expressing cells were also immunolabeled, which may be indicative for specificity. We found that the vast majority of ZsGreen1-containing $\mathrm{NeuN}^{+}$neurons showed immunoreactivity for the mixture of GABAergic cell markers $(86.5 \%, n=1480)$. The lack of immunostaining in $13.5 \%$ of ZsGreen1-expressing neurons may be twofold. First, some GABAergic cells express neurochemical markers at a level below detectability using the applied method. That was the primary reason why we used distinct Cre mouse lines to visualize distinct groups of GABAergic cells in the subsequent experiments. Second, there may be a group of GABAergic cells (e.g., those expressing M2 type of muscarinic acetylcholine receptors) that can be only partially labeled by the cocktail of antibodies. These results collectively show that, in Vgat-IRES-Cre mice, all major GABAergic cell types can be entirely labeled and nonGABAergic neurons are likely to be visualized only marginally, in line with earlier studies (Yamamoto et al., 2018).

Surgical procedures and viral vectors. Anesthesia was induced and maintained with ketamine/xylazine anesthesia. Mice were secured in a stereotaxic frame, and four injections per animal were aimed unilaterally at the following coordinates: $1.5 \mathrm{~mm}$ to bregma (AP), $3.2 \mathrm{~mm}$ lateral to the midline (ML), $4.0 \mathrm{~mm}$ deep from the cortical surface (DV); $1.5 \mathrm{~mm}$ AP, $3.2 \mathrm{~mm}$ ML, $5.0 \mathrm{~mm}$ DV; $2.1 \mathrm{~mm} \mathrm{AP,} 3.2 \mathrm{~mm} \mathrm{ML}, 4.0 \mathrm{~mm} \mathrm{DV}$; and $2.1 \mathrm{~mm}$ AP, $3.2 \mathrm{~mm} \mathrm{ML}, 5.0 \mathrm{~mm} \mathrm{DV}$. Adeno-associated virus (AAV)based constructs engineered to transfect $\mathrm{Cre}^{+}$and $\mathrm{Cre}^{+} / \mathrm{Flp}^{+}$neurons with AAV2/5-EF1a-DIO-EYFP-WPRE-hGH and AAVdj-hSyn-C(on)/F
(on)-EYFP-WPRE, respectively, were obtained from the University of Pennsylvania Vector Core and the University of North Carolina Vector Core, respectively. The virus titers were $3-6 \times 10 \mathrm{e} 12 \mathrm{vg} / \mathrm{ml}$. At each site, $350 \mathrm{nl}$ (total of $1400 \mathrm{nl} /$ hemisphere) of AAV2/5-EF1a-DIO-EYFPWPRE-hGH (flow rate: $50 \mathrm{nl} / \mathrm{min}$ ) was unilaterally injected into the right BLA of 9- to 12-week-old homozygous Pvalb-IRES-Cre, Sst-IRES$\mathrm{Cre}$, and Vip-IRES-Cre mice. To visualize $\mathrm{SST}^{+}$projection neurons in the amygdalar region, $300 \mathrm{nl}$ of AAVretro-EF1a-mCherry-IRES-Flpo obtained from Addgene (titer, $7 \times 10 \mathrm{e} 12 \mathrm{vg} / \mathrm{ml}$ ) was unilaterally injected in the basal forebrain ( $0.25 \mathrm{~mm} \mathrm{AP,} 1.3 \mathrm{~mm} \mathrm{ML}, 4.4 \mathrm{~mm} \mathrm{DV})$ or entorhinal cortex (4.25 mm AP, $3.25 \mathrm{~mm}$ ML, $3.5 \mathrm{~mm} \mathrm{DV}$ ) of Sst-IRES-Cre mice, followed by the injection of AAVdj-hSyn-C(on)/F(on)-EYFPWPRE into the BLA at two AP coordinates as above (total of $400 \mathrm{nl} /$ amygdala). In the case of $3 \mathrm{Npy}^{\mathrm{Cre}} ; \mathrm{Dlx} 5 / 6^{\mathrm{Flp}}$ mice, AAVdj-hSyn-C(on)/F (on)-EYFP-WPRE (total of $1400 \mathrm{nl} /$ hemisphere) was injected into the amygdala using the same coordinates as above. Despite the fact that the same amount of AAVdj was injected into $\mathrm{Npy}{ }^{\mathrm{Cr}} ; \mathrm{Dlx} 5 / 6^{\mathrm{Flp}}$ mice, the spread of the viral infection was smaller as in case of AAV2/5 injection and only the LA was fully infected. Therefore, three additional $\mathrm{Npy}^{\mathrm{Cre}}$; $\mathrm{Dlx} 5 / 6^{\mathrm{Fl} p}$ mice were injected with ML coordinates modified from 3.2 to $2.8 \mathrm{~mm}$, which resulted in full infection of the BA. The injection cannula was slowly withdrawn $5 \mathrm{~min}$ after injection. EYFP expression was allowed for 4-5 weeks, before the animals were killed.

Immunostaining of perfused tissue. Tissue samples for immunostaining from virus-injected and transgenic mice were prepared as for the stereological analysis. To estimate the ratios of inhibitory cell types, sections prepared from AAV-injected Cre mouse lines or transgenic mice were incubated in a mixture of primary antibodies, followed by a 
mixture of secondary antibodies listed in Table 1. To determine the proportion and the distribution of GABAergic boutons lacking immunoreactivity for PV, sections from virus-injected Pvalb-Cre mice were first pepsin-treated for antigen retrieval (Veres et al., 2014). Then, after several washing steps, the sections were incubated in guinea pig anti-VGAT, chicken anti-GFP, mouse anti-neuroligin 2, mouse anti-gephyrin, and rabbit antiAnkyrin G, followed by incubation in a mixture of DyL405-conjugated anti-guinea pig, Alexa488-conjugated anti-chicken, Cy3-conjugated anti-mouse, and Alexa647-conjugated anti-rabbit. To reveal the neurotransmitter characteristics of axons in the contralateral amygdala on injection of viral vectors into the amygdala region of NPY-Cre mice, immunostaining using a mixture of goat anti-GFP and rabbit anti-VGluT1 was performed. To visualize these antibodies, a mixture of Alexa488-conjugated anti-goat and $\mathrm{Cy} 3$-conjugated anti-rabbit was used. After several washings, the sections were mounted and coverslipped with Vectashield (Vector Laboratories) in each case. Multichannel confocal images were obtained using a Nikon A1R or C2 microscope, apochromatic lens (CFI Plan Apo VC 20x NA 0.75 and 60x NA 1.40) ( $z$ stacks, $1 \mu \mathrm{m}$ step size). The image analysis was performed using Neurolucida Explorer.

Electrophysiological slice recordings. Adult (P60-90) Npy-Cre x Ai14, Vgat ${ }^{\mathrm{Cre}}$;CCK-GFPcoIN, $\mathrm{Vip}^{\mathrm{Cre}}$;CCK-GFPcoIN or Sst-IRES-Cre and $\mathrm{Npy}^{\mathrm{Cre}}$; Dlx $5 / 6^{\mathrm{Flp}}$ mice after 4-6 weeks following injection of viral vectors were deeply anesthetized with isoflurane, the brain was quickly removed and placed into icecold solution containing the following (in $\mathrm{mm}$ ): 252 sucrose, $2.5 \mathrm{KCl}, 26 \mathrm{NaHCO}_{3}, 0.5 \mathrm{CaCl}_{2}, 5 \mathrm{MgCl}_{2}$, $1.25 \mathrm{NaH}_{2} \mathrm{PO}_{4}, 10$ glucose, bubbled with $95 \% \mathrm{O}_{2} / 5 \%$ $\mathrm{CO}_{2}$ (carbogen gas). Horizontal $200-\mu \mathrm{m}$-thick brain sections containing the BLA were prepared with a vibratome (VT1200S, Leica Microsystems) and kept in an interface-type holding chamber containing $\mathrm{ACSF}$ at $36^{\circ} \mathrm{C}$ that gradually cooled down to room temperature. ACSF contained the following (in $\mathrm{mm}$ ): $126 \mathrm{NaCl}, 2.5 \mathrm{KCl}, 1.25 \mathrm{NaH}_{2} \mathrm{PO}_{4}, 2 \mathrm{MgCl}_{2}, 2 \mathrm{CaCl}_{2}$, $26 \mathrm{NaHCO}_{3}$, and 10 glucose, bubbled with carbogen gas. After at least a 60-min-long incubation, slices were transferred to a submerged-type recording chamber and perfused with $32^{\circ} \mathrm{C}-34^{\circ} \mathrm{C}$ ACSF with a flow rate of $1.5-2 \mathrm{ml} / \mathrm{min}$.

Recordings were performed under visual guidance using differential interference contrast microscopy (via a model FN-1 Nikon or BX61W Olympus upright microscope) using a $40 \times$ water dipping objective. Fluorescent protein expression in neurons was visualized with the aid of a mercury arc lamp and a CCD camera (Andor Technology). Patch pipettes (5-7 $\mathrm{M} \Omega$ ) for whole-cell recordings were pulled from borosilicate capillaries with inner filament (thin-walled, OD 1.5) using a P1000 pipette puller (Sutter Instrument). In whole-cell recordings, the patch pipette contained a K-gluconate based intrapipette solution as follows (in $\mathrm{mM}$ ): 115 K-gluconate, $4 \mathrm{NaCl}, 2 \mathrm{Mg}$-ATP, 20 HEPES, 0.1 EGTA, 0.3 GTP (sodium salt), and 10 phosphocreatine adjusted to $\mathrm{pH} 7.3$ using $\mathrm{KOH}$, with an osmolarity of $290 \mathrm{mOsm} / \mathrm{L}$. The pipette also contained $0.2 \%$ biocytin. Recordings were performed with a Multiclamp 700B amplifier (Molecular Devices), low-pass filtered at $3 \mathrm{kHz}$, digitized at $10 \mathrm{kHz}$, recorded with an in-house data acquisition and stimulus software
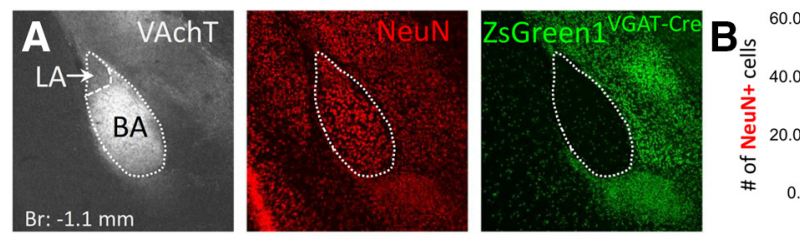

LA
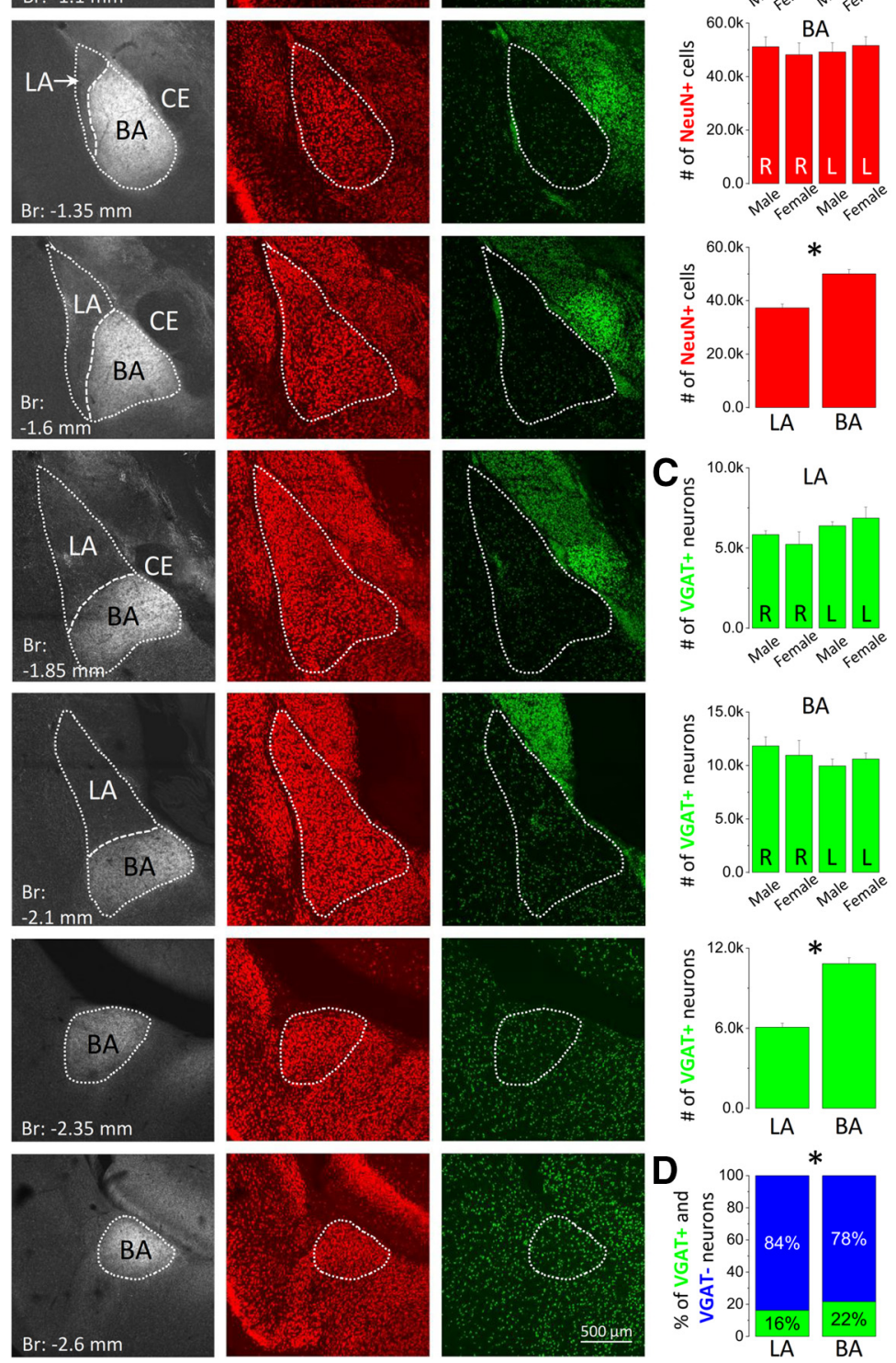

Figure 1. Total number of GABAergic and non-GABAergic neurons estimated in the lateral (LA) and basal nucleus (BA) of the mouse amygdala. $A$, Serial sections containing the two amygdalar nuclei were prepared from an offspring of a Vgat-Cre mouse crossed with an Ai6 reporter mouse. In offspring, ZsGreen1, the reporter protein in Ai6 line, is expressed in GABAergic neurons. NeuN ${ }^{+}$cells lacking ZsGreen1 signal were considered non-GABAergic neurons. The borders of $L A$ and $B A$ were defined on the basis of NeuN immunostaining and VAchT, as VAchT-immunopositive axons are more abundant in the $B A$ than in surrounding structures. Images were taken at the corresponding anterior-posterior coordinates relative to bregma (Br). CE, Central nucleus of the amygdala. $\boldsymbol{B}$, Using unbiased stereology, the total number of neurons expressing NeuN, including both ZsGreen1-containing and lacking cells, were assessed in the LA and BA of both sexes. No difference was observed between the hemispheres and/or sexes in the two nuclei (R, Right; L, Left). In contrast, significantly more neurons were estimated in the BA compared with the LA $\left({ }^{*} p<0.001\right)$. C, Similarly, no difference in the number of GABAergic (i.e., VGAT-expressing) neurons was observed between the hemispheres and/or sexes in the two nuclei. In contrast, the number of GABAergic cells was significantly larger in the $B A\left({ }^{*} p<0.001\right)$. $D$, The ratio of GABAergic neurons between the two amygdalar nuclei was also significantly different $\left({ }^{*} p<0.001\right)$.

(Stimulog, courtesy of Zoltán Nusser, Institute of Experimental Medicine) or Clampex 10.4 (Molecular Devices), and were analyzed with EVAN 1.3 (courtesy of Istvan Mody, Department of Neurology and Physiology, University of California, Los Angeles), Clampfit 10.4 (Molecular Devices), and OriginPro 2018 (OriginLab). 
Table 2. Primary antibodies used in this study

\begin{tabular}{|c|c|c|c|c|c|c|}
\hline Antigen & Source & Catalog \# & Lot \# & Host & Dilution & RRID \\
\hline AnkyrinG & Santa Cruz Biotechnology & sc- 28561 & $\mathrm{E} 2512$ & Rabbit & $1: 500$ & AB_633909 \\
\hline $\mathrm{CB}$ & Synaptic Systems & 214004 & $214004 / 5$ & Guinea pig & $1: 3000$ & $A B \_10550535$ \\
\hline$C B$ & Swant & CB-38a & 9.03 & Rabbit & $1: 5000$ & $A B \_10000340$ \\
\hline CB & Synaptic Systems & 214006 & $214006 / 2$ & Chicken & $1: 1000$ & AB_2619903 \\
\hline$C R$ & Synaptic Systems & 214104 & $214104 / 3$ & Guinea pig & $1: 1000$ & $A B \_10635160$ \\
\hline CR & Swant & $7699 / 3 \mathrm{H}$ & 18299 & Rabbit & $1: 1000$ & $A B \_10000321$ \\
\hline CB1 cannabinoid receptor & Cayman Chemicals & 10006590 & 4574771 & Rabbit & $1: 1000$ & AB_409026 \\
\hline Gephyrin & Synaptic Systems & 147021 & - & Mouse & $1: 1000$ & $A B \_2232546$ \\
\hline GFP & Frontier Institute & GFP-Go-Af1480 & - & Goat & $1: 1000$ & AB_2571574 \\
\hline GFP & Millipore & MAB1083 & 3143158 & Mouse & $1: 5000$ & AB_1587098 \\
\hline GFP & Synaptic Systems & 132006 & $1-2$ & Chicken & $1: 1000$ & AB_2713983 \\
\hline NeuN & Millipore & ABN91 & 3189200 & Chicken & $1: 1000$ & AB_11205760 \\
\hline Neuroligin2 & Synaptic Systems & 129511 & - & Mouse & $1: 1000$ & AB_2619813 \\
\hline nNOS (neuronal) & Abcam & ab1376 & GR3195323-6 & Goat & $1: 5000$ & $A B \_300614$ \\
\hline NPY & ImmunoStar & 22940 & 1112001 & Rabbit & $1: 5000$ & AB_2307354 \\
\hline Kv2.1 & Neuromab & 75-014 & 449-3AK-78D & Mouse & $1: 1000$ & AB_10673392 \\
\hline pro CCK & Frontier Institute & CCK-pro-Rb-Af350 & - & Rabbit & $1: 5000$ & $A B \_2571674$ \\
\hline PV & Swant & PVG-214 & - & Goat & $1: 5000$ & AB_2313848 \\
\hline PV & Synaptic Systems & 195002 & $195002 / 7$ & Rabbit & $1: 500$ & AB_2156474 \\
\hline SST & Synaptic Systems & 366004 & $366004 / 1-3$ & Guinea pig & $1: 500$ & AB_2620126 \\
\hline SST & Peninsula Laboratories & $\mathrm{T}-4103.0050$ & A15819 & Rabbit & $1: 10,000$ & $A B \_518614$ \\
\hline SST & Millipore & MAB354 & 2984147 & Rat & $1: 500$ & AB_2255365 \\
\hline VAchT & Frontier Institute & VAChT-Rb-Af1000 & - & Rabbit & $1: 2000$ & $A B \_2571850$ \\
\hline VGAT & Frontier Institute & VGAT-GP-Af1000 & - & Guinea pig & $1: 1000$ & $A B \_2571624$ \\
\hline VGluT1 & Synaptic Systems & 135302 & - & Rabbit & $1: 1000$ & $A B \_887875$ \\
\hline VIP & ImmunoStar & 20077 & 1513001 & Rabbit & $1: 1000$ & $A B \_572270$ \\
\hline
\end{tabular}

For firing pattern analysis, neurons were recorded in current-clamp mode at a holding potential of $-65 \mathrm{mV}$. Voltage responses were tested with a series of hyperpolarizing and depolarizing square pulses of current with $800 \mathrm{~ms}$ duration and amplitudes between -100 and $100 \mathrm{pA}$ at $10 \mathrm{pA}$ step intervals, then up to $300 \mathrm{pA}$ at $50 \mathrm{pA}$ step intervals, and finally up to $600 \mathrm{pA}$ at $100 \mathrm{pA}$ step intervals.

Identification of recorded interneuron types and immunostaining in slices. Biocytin content of recorded neurons was visualized using Cy3conjugated streptavidin in slices prepared from Vgat ${ }^{\mathrm{Cr}}$;CCK-GFPcoIN $\mathrm{Vip}^{\mathrm{Cre}}$;CCK-GFPcoIN and $\mathrm{Npy}{ }^{\mathrm{Cre}} ; \mathrm{Dlx} 5 / 6^{\mathrm{Flp}}$ mice. Alexa488-conjugated and Alexa647-conjugated streptavidin was used to reveal the biocytinloaded neurons in slices prepared from Npy-Cre x Ail4 mice and SstIRES-Cre mice, respectively. After the visualization of recorded neurons, confocal images of the filled cells were obtained using a confocal microscope (Nikon model C2) under a Plan-Apochromat VC $20 \times$ objective (NA $0.75, z$ step size: $1 \mu \mathrm{m} ; x y: 0.31 \mu \mathrm{m} /$ pixel). Slices (not resectioned) were immunostained with antibodies based on the firing pattern characteristics and features of the dendritic and axonal arbors of the recorded neurons. Incubation of antibodies was performed for $7-8 \mathrm{~d}$ at $4^{\circ} \mathrm{C}$. Putative $\mathrm{CCK}^{+} / \mathrm{CB}^{+}$basket cells were immunostained with rabbit antiCB1 antibody and visualized using DyL405-conjugated donkey anti-rabbit antibody. VIP content was tested by rabbit anti-VIP and visualized using Cy3-conjugated donkey anti-rabbit. To reveal the GFP content of $\mathrm{CB}^{+}$axon terminals in $\mathrm{Vgat}{ }^{\mathrm{Cre}}$;CCK-GFPcoIN mice, sections were incubated in a mixture of chicken anti-GFP and rabbit anti-CB1, followed by the visualization of these antibodies using Alexa488-conjugated donkey anti-chicken and Cy3-conjugated donkey anti-rabbit. The presence of nNOS and PV in SST ${ }^{+}$inhibitory cells was revealed with goat anti-nNOS and rabbit anti-PV using DyL405-conjugated donkey antigoat first and subsequently using donkey anti-rabbit in 2 cases, where no nNOS immunoreactivity was seen in the soma of tested neurons. To visualize the Kv2.1 type of voltage-gated potassium channels in slices, mouse anti-Kv2.1 antibody was used, which was developed by Cy3-conjugated donkey anti-mouse antibody.

The neurochemical content of biocytin-filled $\mathrm{NPY}^{+}$interneurons was tested with the use of the following primary antibodies: rabbit anti$\mathrm{PV}$, guinea pig anti-SST, goat anti-nNOS, chicken anti-calbindin (CB), guinea pig anti-CB, or rabbit anti-CB1. The following secondary antibodies were used to visualize these primary antibodies: DyL405- conjugated donkey anti-rabbit, DyL405-conjugated donkey anti-guinea pig, DyL405-conjugated donkey anti-chicken, DyL405-conjugated donkey anti-goat, Alexa647-conjugated donkey anti-rabbit, Cy5-conjugated donkey anti-goat, or Cy5-conjugated donkey anti-guinea pig.

To reveal the axon initial segments, rabbit anti-Ankyrin $G$ was used after antigen retrieval (Veres et al., 2014). This antibody was visualized with Alexa647-conjugated donkey anti-rabbit. All images were obtained using a confocal microscope (Nikon model C2) under a Plan Apo VC $60 \times$ objective (NA 1.4, $z$ step size: $0.15-0.2 \mu \mathrm{m} ; x y: 0.08-0.10 \mu \mathrm{m} /$ pixel). For the quantification of the input on axon initial segments, the images were subsequently deconvolved with Huygens software (SVI) and analyzed using the "Cell counter" and "SNT" plugins in the ImageJ software.

All antibodies used in this study are listed in Tables 2 and 3.

Reconstruction of biocytin-loaded cells. The dendritic and axonal arbors of the intracellularly filled neurons were reconstructed with Neurolucida 10.53 software, using confocal stacks acquired of the cell. The drawings of each neuron were analyzed with Neurolucida Explorer, and the values were corrected for shrinkage and flattening of the tissue (correction factor in the $z$ axis: 1.7; no correction in the $x$ and $y$ axis). Branched structure analysis was used to study the dendritic length and number of nodes. Sholl analysis was used to estimate the complexity of the dendritic arbor by determining the number of processes crossing concentric spheres centered on the cell soma with $50 \mu \mathrm{m}$ increments in their radius. Close apposition of a labeled bouton onto its target was defined as no apparent gap between the two profiles in $3 \mathrm{D}$ view.

Statistical analysis. Data are presented as mean \pm SEM, if not indicated otherwise. Statistical significance $(p<0.05)$ was assessed by $t$ test for comparison of data with a normal distribution, whereas KruskalWallis ANOVA, Dunn's test, Mann-Whitey (MW) $U$ test, and Kolmogorov-Smirnov test were used for datasets with a non-normal distribution.

\section{Results}

Using unbiased stereology, we assessed the number of GABAergic neurons in the LA and BA. Our investigations were performed both in the right and left hemispheres of male and 
Table 3. Secondary antibodies used in this study

\begin{tabular}{|c|c|c|c|c|c|c|}
\hline Antibody & Source & Catalog \# & Lot \# & Host & Dilution & RRID \\
\hline AlexaFluor-488 anti-chicken & Jackson ImmunoResearch Laboratories & 703-545-155 & 146581 & Donkey & $1: 500$ & AB_2340375 \\
\hline AlexaFluor-488 anti-goat & Jackson ImmunoResearch Laboratories & $705-545-147$ & 143223 & Donkey & $1: 500$ & AB_2336933 \\
\hline AlexaFluor-488 anti-mouse & Molecular Probes/Thermo Fisher Scientific & A21202 & 2090565 & Donkey & 1:500 & $A B \_141607$ \\
\hline Cy3 anti-chicken & Jackson ImmunoResearch Laboratories & $703-165-155$ & 124400 & Donkey & 1:500 & AB_2340363 \\
\hline Cy3 anti-goat & Jackson ImmunoResearch Laboratories & $705-165-147$ & 111783 & Donkey & $1: 500$ & AB_2307351 \\
\hline Cy3 anti-mouse & Jackson ImmunoResearch Laboratories & $715-165-151$ & 45374 & Donkey & 1:400 & $A B \_2315777$ \\
\hline Cy5 anti-goat & Jackson ImmunoResearch Laboratories & $705-175-147$ & 111314 & Donkey & $1: 200$ & AB_2340415 \\
\hline Cy5 anti-guinea pig & Jackson ImmunoResearch Laboratories & $706-175-148$ & 113929 & Donkey & $1: 400$ & AB_2340462 \\
\hline DyL405 anti-chicken & Jackson ImmunoResearch Laboratories & $703-475-155$ & 140264 & Donkey & $1: 500$ & AB_2340373 \\
\hline DyL405 anti-goat & Jackson ImmunoResearch Laboratories & $705-475-003$ & - & Donkey & 1:500 & $A B \_2340426$ \\
\hline DyL405 anti-guinea pig & Jackson ImmunoResearch Laboratories & $706-475-148$ & 129848 & Donkey & $1: 500$ & AB_2340470 \\
\hline DyL405 anti-rabbit & Jackson ImmunoResearch Laboratories & $711-475-152$ & 98072 & Donkey & 1:500 & $A B \_2340616$ \\
\hline
\end{tabular}

female mice. To estimate the total number of GABAergic and non-GABAergic neurons, we counted the number of $\mathrm{NeuN}^{+}$cells expressing ZsGreen1 (i.e., GABAergic neurons) or lacking this reporter protein (i.e., non-GABAergic neurons) in the LA and BA of mice generated by breeding of Vgat-Cre and Ai6 mice (Fig. 1; Table 4). Comparison of the number of all neurons between hemispheres revealed no difference: a similar number of neurons was found in the right and left LA ( $p=0.29$ for males, $p=0.17$ for females) as well as in the right and left BA ( $p=0.72$ for males, $p=0.57$ for females) (Fig. $1 B$ ). In addition, we found no sex difference in the number of all neurons, when the corresponding amygdalar nuclei were compared ( $p=0.67$ for the right LA between males and females; $p=0.08$ for the left LA between males and females; $p=0.63$ for the right BA between males and females; $p=0.64$ for the left BA between males and females) (Fig. $1 B$ ). However, a larger number of neurons were found in the BA than LA $(37,304 \pm 1439$ in the LA; $50,044 \pm 1649$ in the $\mathrm{BA} ; n=12$, pooled data from both males and females as well as from right and left hemispheres, $p<0.001$ ) (Fig. $1 B$ ).

Similarly, comparison of the number of GABAergic neurons between hemispheres revealed no difference; that is, a comparable number of $\mathrm{VGAT}^{+}$neurons was observed in the right and left LA ( $p=0.20$ for males, $p=0.19$ for females) as well as in the right and left BA ( $p=0.16$ for males, $p=0.83$ for females) (Fig. $1 C)$. Moreover, we have not found a sex difference in the number of GABAergic neurons, when the corresponding amygdalar nuclei were compared ( $p=0.52$ for the right LA between males and females; $p=0.56$ for the left LA between males and females; $p=0.62$ for the right BA between males and females; $p=0.49$ for the left BA between males and females) (Fig. 1C). Yet, a significantly larger number of $\mathrm{VGAT}^{+}$neurons were identified in the BA than LA $(6077 \pm 298$ in the LA; $10,839 \pm 441$ in the BA; $n=12, p<0.001$ ) (Fig. $1 C$ ). The larger difference in the number of GABAergic neurons between the LA and BA compared with the difference in the number of total neurons between these two nuclei predicted that the proportion of $\mathrm{VGAT}^{+}$neurons in the neuronal populations should be different. Indeed, the ratio of GABAergic neurons in the BA was significantly larger than in the LA $(16.3 \pm 0.5 \%$ in the LA; $21.6 \pm 0.4 \%$ in the BA; $n=12$, $p<0.001$ ) (Fig. 1D). These data collectively revealed that the LA contains a lower number of neurons than the BA, and the
Table 4. Estimation of the number of GABAergic $\left(\mathrm{VGAT}^{+} / \mathrm{NeuN}^{+}\right)$and all neurons $\left(\mathrm{NeuN}^{+}\right.$), including both GABAergic and non-GABAergic neurons in the LA and $B A$ using unbiased stereology

\begin{tabular}{|c|c|c|c|c|c|}
\hline & \multirow[b]{2}{*}{ Animal ID } & \multicolumn{2}{|l|}{ LA } & \multicolumn{2}{|l|}{$B A$} \\
\hline & & $\begin{array}{l}\mathrm{VGAT}^{+} / \\
\mathrm{NeuN}^{+} \#\end{array}$ & All NeuN ${ }^{+} \#$ & $\begin{array}{l}\text { VGAT }^{+} / \\
\text {NeuN }^{+} \#\end{array}$ & All NeuN ${ }^{+} \#$ \\
\hline \multirow[t]{3}{*}{ Male_right } & Mouse 1 & 5596 & 35,337 & 11,051 & 46,925 \\
\hline & Mouse 2 & 5585 & 35,646 & 10,937 & 48,101 \\
\hline & Mouse 3 & 6317 & 36,180 & 13,507 & 58,462 \\
\hline \multirow[t]{3}{*}{ Female_right } & Mouse 4 & 3683 & 26,025 & 9004 & 43,899 \\
\hline & Mouse 5 & 5834 & 32,994 & 10,214 & 43,567 \\
\hline & Mouse 6 & 6170 & 41,439 & 13,653 & 57,025 \\
\hline \multirow[t]{3}{*}{ Male_left } & Mouse 1 & 6778 & 34,971 & 8755 & 43,398 \\
\hline & Mouse 2 & 6469 & 38,774 & 10,962 & 55,323 \\
\hline & Mouse 3 & 5896 & 39,040 & 10,156 & 48,941 \\
\hline \multirow[t]{3}{*}{ Female_left } & Mouse 4 & 8031 & 44230 & 9569 & 46222 \\
\hline & Mouse 5 & 5655 & 39434 & 10809 & 51056 \\
\hline & Mouse 6 & 6908 & 43578 & 11449 & 57605 \\
\hline
\end{tabular}

fraction of GABAergic neurons in the LA is smaller than in the BA. Importantly, we observed no difference in the number of neurons either between hemispheres or sexes.

Next, we looked at whether the ratios of GABAergic cells in two amygdala nuclei at different anterior-posterior distances from bregma show any difference (Table 5). In the LA, no substantial change in the ratio of inhibitory cells could be noticed (Kruskal-Wallis ANOVA, $p>0.07$ ). In contrast, there was a significant difference in the ratio of GABAergic cells in the BA at distinct anterior-posterior levels (Kruskal-Wallis ANOVA, $p<0.001)$. Specifically, the proportion of GABAergic cells at the most posterior part of the BA (at $-2.6 \mathrm{~mm}$ from bregma) was significantly lower than those found at the distance of -1.85 and $-2.1 \mathrm{~mm}$. In addition, the ratio of GABAergic cells was also lower at $-1.35 \mathrm{~mm}$ compared with that observed at $-2.1 \mathrm{~mm}$ (Table 5). Interestingly, the portion of inhibitory neurons "peaked" at $-2.1 \mathrm{~mm}$ for both the LA and BA. These data suggest that the inhibition at distinct anterior-posterior distances, at least in the BA, may be different.

As GABAergic neurons can be divided into several functional categories in cortical networks (Kepecs and Fishell, 2014), we next aimed to estimate the ratio of these major inhibitory neuron types within the circuits of the LA and BA using viral techniques combined with immunocytochemistry. 
Table 5. The ratio of GABAergic cells in the lateral (LA) and basal (BA) amygdala nuclei at different anterior-posterior distances from bregma ${ }^{a}$

\begin{tabular}{|c|c|c|c|c|c|c|c|}
\hline & \multicolumn{7}{|c|}{ Distance from bregma (mm) } \\
\hline LA & & $12.9 \pm 1.1$ & $14.6 \pm 1.1$ & $15.3 \pm 1.2$ & $17.8 \pm 0.8$ & $16.3 \pm 2.3$ & \\
\hline \multirow[t]{3}{*}{ BA } & $20.8 \pm 3.9$ & $19.5 \pm 1.2$ & $22.5 \pm 1.8$ & $25.1 \pm 0.9$ & $25.9 \pm 0.6$ & $20.6 \pm 0.9$ & $16.5 \pm 1.3$ \\
\hline & $n=10$ & $n=12$ & $n=12$ & $n=12$ & $n=12$ & $n=12$ & $n=11$ \\
\hline & \multicolumn{7}{|c|}{ Normalized ratio of GABAergic cells at different distances from bregma (\%) } \\
\hline
\end{tabular}

$a_{n}$ indicates the number of sections used for the calculation.

${ }^{*} p=0.03 ;{ }^{* *} p=0.0022 ;{ }^{* * *} p<0.001$; Dunn's test.

\section{$\mathrm{PV}^{+}$interneurons targeting the perisomatic region of the principal cells}

First, we assessed the proportion of PV-containing interneurons in the two amygdala nuclei by labeling $\mathrm{PV}^{+}$interneurons in Pvalb-Cre mice using a viral vector (Fig. 2A-C; Table 6). We found that significantly more $\mathrm{PV}^{+}$interneurons were present in the BA than in the LA (Table 6). Previous studies uncovered that $\mathrm{PV}$ is expressed in two types of amygdalar interneurons that target the perisomatic region of principal neurons (Smith et al., 1998; Muller et al., 2006). $\mathrm{PV}^{+}$basket cells expressing CB innervate the soma and the proximal dendrites of principal neurons, whereas $\mathrm{PV}^{+}$axo-axonic cells lacking $\mathrm{CB}$ form synaptic contacts on axon initial segments (Bienvenu et al., 2012; Veres et al., 2014, 2017; Vereczki et al., 2016). Therefore, by using immunostaining against $\mathrm{CB}$, we separated these two PV-containing interneuron types and estimated their ratio (Fig. 2D). In line with earlier findings (McDonald and Betette, 2001; McDonald and Mascagni, 2001), CB was present in the majority of $\mathrm{PV}^{+}$interneurons (Fig. $2 E)$; that is, $\mathrm{PV}^{+}$basket cells are the most abundant interneurons among $\mathrm{PV}^{+}$GABAergic neurons (Table 6). Based on our counting, $\mathrm{PV}^{+} / \mathrm{CB}^{+}$basket cells constitute $\sim 2.2 \%$ and $\sim 4.7 \%$ of all neurons in the LA and BA, respectively.

\section{One-third of axo-axonic cells lack PV}

Previous studies have shown that some axo-axonic cells may lack PV in cortical areas (He et al., 2016; Paul et al., 2017); thus, the ratio of axo-axonic cells determined solely on the basis of PV expression (LA: $19.9 \pm 4.2 \%$; BA: $15.9 \pm 1.4 \%$ of all $\mathrm{PV}^{+}$interneurons) could be underestimated in the amygdala as well. To test the presence of amygdalar axo-axonic cells lacking PV, we examined the PV content of GABAergic boutons forming synaptic contacts with axon initial segments. The presence of a synapse between a closely apposed bouton and an axon initial segment was assessed by visualizing two inhibitory synapse-specific proteins, gephyrin and neuroligin 2 using immunostaining (Veres et al., 2014). In virus-injected Pvalb-Cre mice, the GFP content of boutons was indicative for PV expression, whereas GABAergic phenotype of axon terminals was revealed by immunostaining against VGAT (Fig. 3A). We observed that the minority $(\sim 32 \%)$ of $\mathrm{VGAT}^{+}$axon terminals forming synaptic contacts with Ankyrin G-labeled axon initial segments originated from $\mathrm{PV}^{-}$ axo-axonic cells in both amygdalar nuclei (LA: $32.2 \pm 2.8 \%$; BA: $32.1 \pm 1.7 \%, n=14-14$ axon initial segments, 2 animals) (Fig. $3 B$ ). If we assume that $\mathrm{PV}^{+}$and $\mathrm{PV}^{-}$axo-axonic cells in the LA and $\mathrm{BA}$ give rise to a similar number of axonal boutons and contact the individual axon initial segments with a similar number of synapses, then $\sim 30 \%$ of this inhibitory cell type cannot be labeled in Pvalb-Cre mice. By summing up the ratio of $\mathrm{PV}^{+} / \mathrm{CB}^{-}$ interneurons (i.e., $\mathrm{PV}^{+}$axo-axonic cells) and $\mathrm{PV}^{-}$axo-axonic cells, the ratio of all axo-axonic cells can be $0.8 \%$ of all neurons in the LA and $1.3 \%$ in the BA.

Next, we asked whether $\mathrm{PV}^{-}$axo-axonic cells follow the same innervation strategy as $\mathrm{PV}^{+}$axo-axonic cells. Our previous investigations revealed that $\mathrm{PV}^{+}$axo-axonic cells in the BA prefer to innervate that part of the axon initial segments where the action potential generation has the highest likelihood (Veres et al., 2014). Therefore, we compared the number of $\mathrm{PV}^{+}$and $\mathrm{PV}^{-} /$ $\mathrm{VGAT}^{+}$axon terminals along axon initial segments both in the LA and BA. We found that in both nuclei the spatial distribution of boutons originating from the two neurochemically different axo-axonic cells were similar $\left(119 \mathrm{PV}^{-} / \mathrm{VGAT}^{+}\right.$boutons and 251 $\mathrm{PV}^{+}$boutons examined along 14 axon initial segments in the LA, $p=0.23$; $196 \mathrm{PV}^{-} / \mathrm{VGAT}^{+}$boutons and $415 \mathrm{PV}^{+}$boutons examined along 14 axon initial segments in the BA, $p=0.89$, Kolmogorov-Smirnov test, 2 mice) (Fig. $3 C$ ). These results indicate that axo-axonic cells, regardless of their PV content, preferentially target a given portion of axon initial segments both in the LA and BA. However, the preferentially targeted portion measured from the onset of the Ankyrin G-labeled profiles was different in the LA and BA $(p<0.0001$, Kolmogorov-Smirnov test; Fig. $3 C$ ). Of all GABAergic boutons along the axon initial segments $\left(\mathrm{PV}^{+}\right.$and $\mathrm{PV}^{-}$together), 60\% was found between 10 and $25 \mu \mathrm{m}$ in the LA and 12 and $35 \mu \mathrm{m}$ in the BA. Taking into account that the length of the Ankyrin G-immunostained profiles in the LA was significantly shorter than in the BA (LA: $31.9 \pm 1.2 \mu \mathrm{m}, n=14$; BA: $43.7 \pm 1.7 \mu \mathrm{m}, n=14$; $p<0.001$; Fig. $3 C$ ), the relative onset and extent of that portion of axon initial segments, which was covered by the majority of inhibitory inputs, was rather similar in both nuclei. Specifically, $60 \%$ of all GABAergic boutons were spread between $31.3 \%$ and $78.6 \%$ of the length of axon initial segment in the LA and between $27.4 \%$ and $80 \%$ in the BA. These observations thus suggest that the relative length for spike generation along the axon initial segment densely covered by GABAergic boutons is rather similar in the LA and BA principal cells (Veres et al., 2014).

\section{$\mathrm{CCK}^{+} / \mathrm{CB1}^{+}$basket cells}

In addition to the axo-axonic cells and $\mathrm{PV}^{+}$basket cells, basket cells expressing CCK and CB1 contribute substantially to GABAergic innervation of the perisomatic region of principal cells in the BA (Vereczki et al., 2016). To estimate the proportion of $\mathrm{CCK}^{+} / \mathrm{CB}^{+}$basket cells in the two amygdala nuclei, we generated a novel mouse line, BAC-CCK-GFPcoIN_sb, in which the GFP expression in $\mathrm{CCK}^{+}$neurons is controlled in a Cre-dependent manner. By crossing this new mouse line with Vgat-Cre mice, GFP expression in the LA and BA (and in other cortical regions) was found to be restricted to the $\mathrm{CCK}^{+}$GABAergic cells 




Figure 2. Ratio of PV-expressing interneurons in the LA and BA. $\boldsymbol{A}$, Schematic of the strategy for targeting PV-expressing interneurons in the amygdala. $\boldsymbol{B}$, Representative images of EYFP expression after virus transfection taken at the corresponding anterior-posterior coordinates (in $\mathrm{mm}$ ) relative to bregma. As EYFP labeling was enhanced by immunostaining with an antibody developed against GFP, we refer to the enhanced EYFP signal as GFP here and in the latter figures. C, Representative example of the amygdalar region taken at a higher magnification. Scale bar, $500 \mu \mathrm{m}$. D, Majority of GFP-labeled neurons in Pvalb-Cre mice contain CB (arrows), whereas a minority of GFP-expressing interneurons lack immunopositivity for this $\mathrm{Ca}^{2+}$ binding protein (open arrowheads). Scale bars, $50 \mu \mathrm{m}$. $E$, The percentage of $\mathrm{PV}^{+}$GABAergic cells in the $\mathrm{LA}$ and $\mathrm{BA}$ is different (top, ${ }^{*} p<0.001$ ). In contrast, there is no difference in the ratio of $\mathrm{PV}^{+}$interneurons expressing $C B$ in the two amygdalar nuclei (bottom).

Table 6. Fraction of distinct types of GABAergic cells in the LA and BA ${ }^{a}$

\begin{tabular}{|c|c|c|c|c|c|c|c|}
\hline Neuron types & $\begin{array}{l}\text { LA (\% of inhibitory } \\
\text { neurons) }\end{array}$ & $\begin{array}{l}\text { No. of } \\
\text { NeuN }^{+} \\
\text {cells }\end{array}$ & $\begin{array}{l}\text { No. of } \\
\text { sections }\end{array}$ & $\begin{array}{l}\text { BA (\% of inhibitory } \\
\text { neurons) }\end{array}$ & $\begin{array}{l}\text { No. of } \\
\text { NeuN }^{+} \\
\text {cells }\end{array}$ & $\begin{array}{l}\text { No. of } \\
\text { sections }\end{array}$ & $t$ test $(p)$ \\
\hline All PV ${ }^{+}$ & $2.8 \pm 0.4$ & 4824 & 7 & $5.6 \pm 0.3$ & 8101 & 12 & $<0.001^{*}$ \\
\hline $\begin{array}{l}\mathrm{CCK}^{+} \text {GABAergic cells in } \\
\text { Vgat }{ }^{\text {ree }} ; \text {;CK-GFPcolN }\end{array}$ & $1.1 \pm 0.3$ & 7768 & 10 & $2.0 \pm 0.2$ & 8815 & 12 & $0.0057^{*}$ \\
\hline proCCK $^{+}$in Vgat ${ }^{\text {Cre }} ;$ CCK-GFPcolN & $53.4 \pm 2.3 \%$ of all $\mathrm{GFP}^{+}$interneurons & & & $62.8 \pm 1.9 \%$ of all $\mathrm{GFP}^{+}$interneurons & & & $0.024^{*}$ \\
\hline $\mathrm{SST}^{+} \mathrm{nNOS}^{+}$ & $41.6 \pm 5.4 \%$ of all SST ${ }^{+}$neurons & & & $25 \pm 5.4 \%$ of all $\mathrm{SST}^{+}$neurons & & & $0.043^{*}$ \\
\hline All $\mathrm{NPY}^{+}$GABAergic cells & $3.8 \pm 0.3$ & 10,458 & 12 & $8.1 \pm 0.7$ & 6931 & 11 & $<0.001^{*}$ \\
\hline $\mathrm{NPY}^{+} \mathrm{PV}^{+}$ & $23.7 \pm 1.9 \%$ of all $\mathrm{NPY}^{+}$GABAergic cells & & & $29.7 \pm 2.7 \%$ of all $\mathrm{NPY}^{+}$GABAergic cells & & & 0.085 \\
\hline $\mathrm{NPY}^{+} \mathrm{SST}^{+}$ & $30.9 \pm 3.6 \%$ of all $\mathrm{NPY}^{+}$GABAergic cells & & & $25.5 \pm 3.0 \%$ of all $\mathrm{NPY}^{+}$GABAergic cells & & & 0.26 \\
\hline Neurogliaform cells & $46.6 \pm 4.7 \%$ of all $\mathrm{NPY}^{+}$GABAergic cells & & & $42.9 \pm 2.8 \%$ of all $\mathrm{NPY}^{+}$GABAergic cells & & & 0.51 \\
\hline
\end{tabular}

${ }^{a}$ In each case, the counting was performed in sections prepared from 3 mice.

*Significant difference. 
A
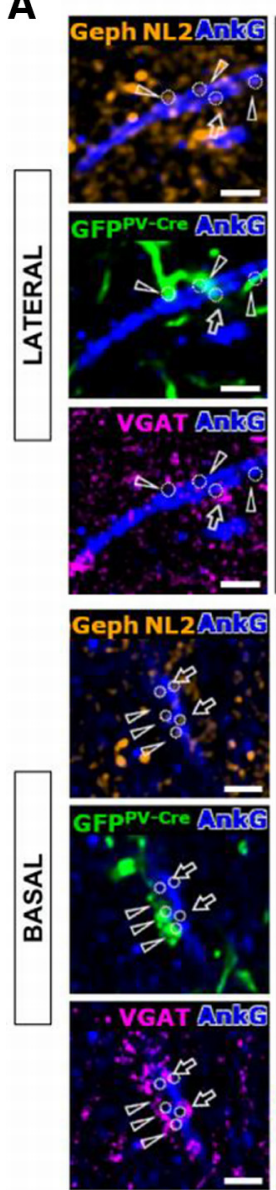

B
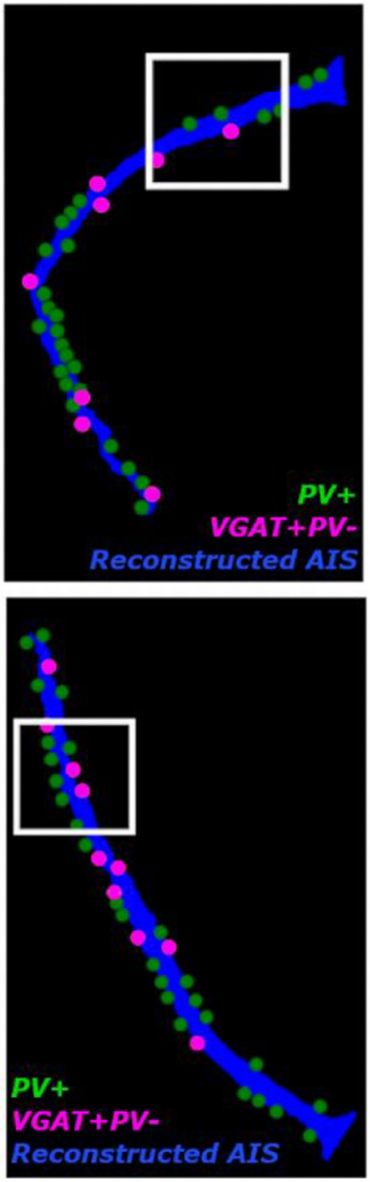
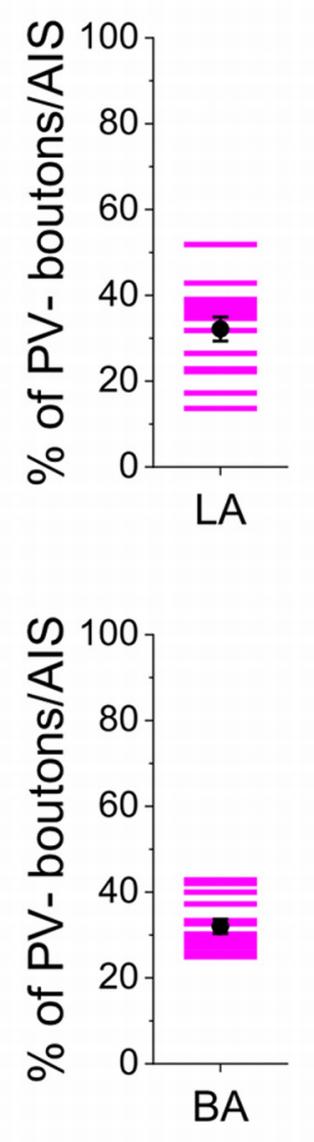

C
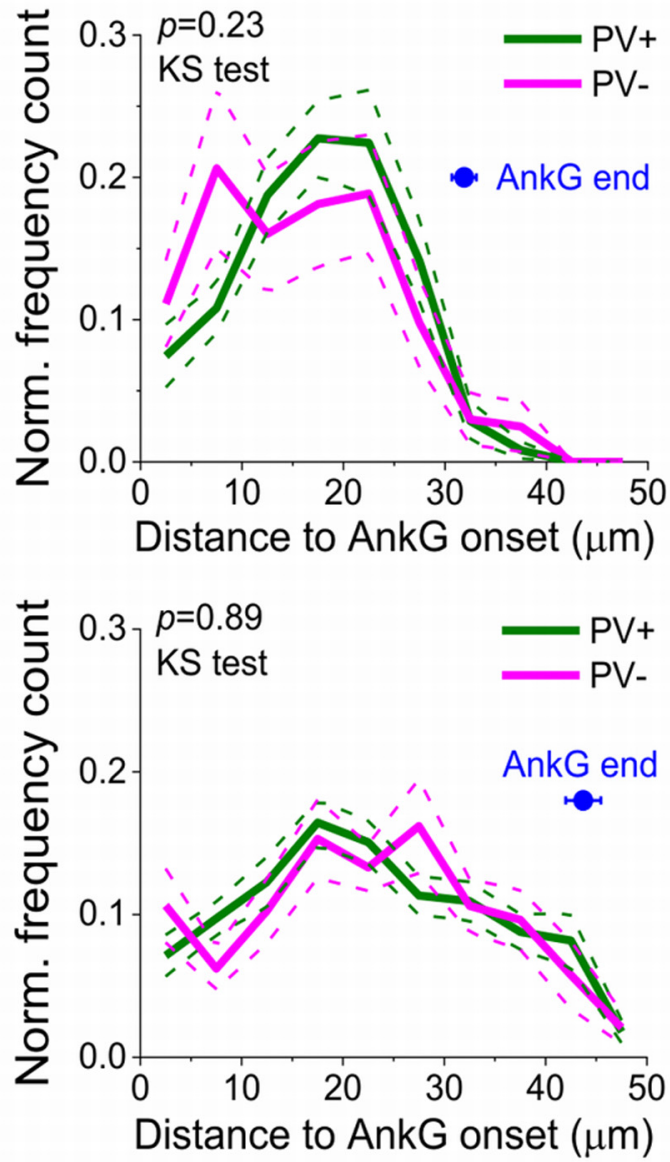

Figure 3. One-third of GABAergic boutons apposing axon initial segments lack PV both in the LA and BA. $A$, Examples of axon initial segments receiving synaptic contacts from both PV ${ }^{+}$ (arrowhead) and PV boutons (arrows). PV-expressing boutons were visualized with GFP in Pvalb-Cre mice using a viral vector, whereas PV-immunonegative axon terminals were determined by immunostaining against VGAT. Synaptic contacts between the boutons and Ankyrin $G$ (AnkG)-labeled axon initial segments were revealed by the presence of two inhibitory synapse-specific proteins, gephyrin (Geph) and neuroligin 2 (NL2). Scale bars, $2 \mu \mathrm{m}$. B, A substantial portion of GABAergic boutons forming synaptic contacts with axon initial segments lacked GFP content, indicative for the absence of PV expression ( $n=14-14$ axon initial segments in the LA and BA were reconstructed). $C_{\text {, The spatial distribution of PV }}^{+}$and PV ${ }^{-}$axon terminals along Ankyrin G-immunostained profiles was similar (Kolmogorov-Smirnov test), indicating that axo-axonic cells regardless of their PV content prefer to innervate a given portion of axon initial segments. Solid line indicates mean. Dashed line indicates SEM. Blue dots represent the average length of the reconstructed Ankyrin G-immunoreactive profiles.

in offspring (i.e., in Vgat ${ }^{\text {Cre }}$;CCK-GFPcoIN mice) (Fig. 4A). To uncover which interneuron types express GFP under CCK promoter in these mice, we performed whole-cell recordings in green neurons in slice preparations followed by neurochemical analysis of the recorded neurons $(n=38,10$ in the LA and 28 in the BA). Only those interneurons were included in the analysis that could be tested for immunoreactivity of CB1 and/or VIP. Our investigations revealed that the vast majority of GFPexpressing interneurons was $\mathrm{CCK}^{+} / \mathrm{CB}^{+}$basket cell $(71.1 \%$, $n=38$ recorded green neurons) as these interneurons had axon terminals immunoreactive for CB1 (27 of 27) (Fig. 4B). The minority of recorded neurons $(28.9 \%, n=38$ recorded green cells) was found to be immunonegative for CB1 ( 8 of 8 tested for axon terminals) but showed immunopositivity for VIP in the soma (4 of 4 tested) (Fig. $4 C$ ). This latter interneuron population had small somata and resembled interneuron-selective interneurons based on their morphologic appearance and spiking features (Fig. 4D; Table 7) (Rhomberg et al., 2018). To confirm that a portion of $\mathrm{VIP}^{+}$interneuron-selective interneurons can be labeled in the BAC-CCK-GFPcoIN_sb mouse line, we crossed these mice with Vip-Cre mice. In their offspring (i.e., in Vip ${ }^{\mathrm{Cre}}$;CCKGFPcoIN mice), we observed $\mathrm{GFP}^{+}$interneurons with small somata that were immunopositive for VIP (LA: 95\%, $n=64$; BA:
96\%, $n=75,3$ mice), but lacked immunoreactivity for proCCK (LA: $96 \%, n=50$; BA: 98.7\%, $n=78,3$ mice) (Fig. $4 E, F)$. We performed whole-cell recordings from small $\mathrm{GFP}^{+}$interneurons in slices prepared from in Vip ${ }^{\text {Cre }}$;CCK-GFPcoIN mice. Both the morphologic appearance, including short dendrites and locally ramified axon collaterals and single-cell features of recorded interneurons $(n=5)$, were similar to those small green interneurons that were sampled in Vgat ${ }^{\mathrm{Cre}}$;CCK-GFPcoIN mice (Fig. 4G; Table 7). Importantly, both the morphologic appearance and firing properties of small green interneurons recorded either in $\mathrm{Vgat}^{\mathrm{Cre}}$; CCK-GFPcoIN mice or Vip ${ }^{\mathrm{Cre}}$;CCK-GFPcoIN mice were comparable with those reported earlier for $\mathrm{VIP}^{+}$interneurons in the amygdala (Rhomberg et al., 2018). In summary, these results collectively suggest that, in Vgat ${ }^{\mathrm{Cre}}$;CCK-GFPcoIN mice, $\mathrm{CCK}^{+}$/ $\mathrm{CB}^{+}$basket cells with large somata are labeled predominantly, while $\mathrm{GFP}^{+}$interneurons with small somata are $\mathrm{VIP}^{+}$interneuronselective interneurons. Thus, by using proCCK antibody, which does not stain $\mathrm{VIP}^{+}$interneuron-selective interneurons under our circumstances, the number of $\mathrm{CCK}^{+} / \mathrm{CB}^{+}$basket cells can be estimated accurately in $\mathrm{Vgat}^{\mathrm{Cre}}$;CCK-GFPcoIN mice.

As a next step, we first assessed the ratio of $\mathrm{CCK}^{+}$interneurons in the LA and BA in Vgat ${ }^{\text {Cre }}$;CCK-GFPcoIN mice (Fig. 5A$C)$ and found significantly different number of these GABAergic 
cells in the two nuclei (Fig. 5E; Table 6). Then, we estimated the fraction of $\mathrm{CCK}^{+} / \mathrm{CB}^{+}$basket cells within the population of $\mathrm{CCK}^{+}$interneurons. As proCCK immunostaining readily labels basket cells, but not $\mathrm{VIP}^{+}$interneuronselective interneurons, we immunostained those sections that were used for calculation of the ratio of $\mathrm{GFP}^{+}$interneurons in the amygdalar nuclei and counted the number of proCCK ${ }^{+}$neurons (Fig. 5D). However, we observed that there was a non-negligible amount of proCCK ${ }^{+}$interneurons that were not labeled in the transgenic mice: 17 proCCK ${ }^{+} / \mathrm{GFP}^{-}$interneurons versus 116 $\mathrm{GFP}^{+}$interneurons in the LA $(10 \mathrm{sec}-$ tions, 3 mice) and 46 proCCK $^{+} / \mathrm{GFP}^{-}$ interneurons versus $180 \mathrm{GFP}^{+}$interneurons in the BA (12 sections, 3 mice) (Fig. 5D). The perimeter of these proCCK $^{+} / \mathrm{GFP}^{-}$interneurons was $45.4 \pm 7.6 \mu \mathrm{m}(n=63)$, similar to the perimeter of the biocytin-labeled $\mathrm{CCK}^{+} /$ $\mathrm{CB}^{+}{ }^{+}$basket cells $(48.1 \pm 2.4 \mu \mathrm{m}, n=16$, $p=0.3)$. Therefore, we assume that proCCK antibody used in our study labels $\mathrm{CCK}^{+} / \mathrm{CB}^{+}$basket cells in the amygdala, the majority of which expresses GFP (LA: 78.5\%, $n=79$; BA: $71.1 \%, n=159)$.

To support the estimation of GFP expression in $\mathrm{CCK}^{+} / \mathrm{CB}^{+}$basket cells with an independent investigation, we evaluated the GFP content of the axon terminals originating from $\mathrm{CCK}^{+} / \mathrm{CB} 1^{+}$ basket cells using immunostaining against CB1 in $\mathrm{Vgat}^{\mathrm{Cre}}$;CCK-GFPcoIN mice. The analysis revealed that GFP signal was present in $63.5 \pm 6.3 \%$ and $66.7 \pm 4.9 \%$ of $\mathrm{CB}^{+}$boutons in the LA ( $n=1157$ boutons, 13 sections, 4 mice) and in the BA ( $n=2025$ boutons, $10 \mathrm{sec}$ tions, 4 mice), respectively.

Based on these two distinct immunostainings, our results strongly suggest that $\sim 30 \%-35 \%$ of $\mathrm{CCK}^{+} / \mathrm{CB}^{+}$basket cells do not express GFP in $\mathrm{Vgat}^{\mathrm{Cre}}$;CCKGFPcoIN mice. Taking into account that a large portion, but not all, of $\mathrm{GFP}^{+}$ interneurons are basket cells (LA: 53.4\%; BA: 62.8\%; Fig. 5E; Table 6) and at least one-third of $\mathrm{CCK}^{+} / \mathrm{CB} 1^{+}$basket cells are not labeled in these transgenic mice, we propose that the ratio of this basket cell type is $\sim 0.9 \%$ in the LA and $1.9 \%$ in the BA among all neurons.

\section{Interneuron-selective interneurons expressing VIP and/or CR}

Next, we investigated the fraction of interneuron-selective interneurons in the LA and BA. Previous studies have established that VIP and CR are reliable markers for these GABAergic

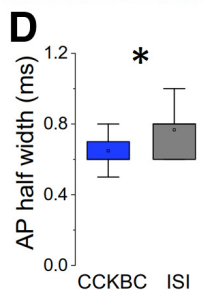

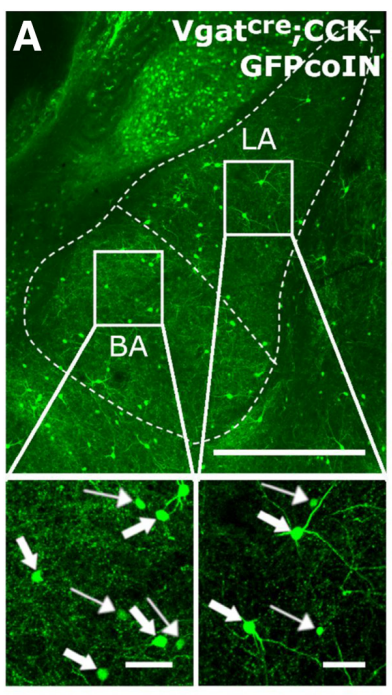
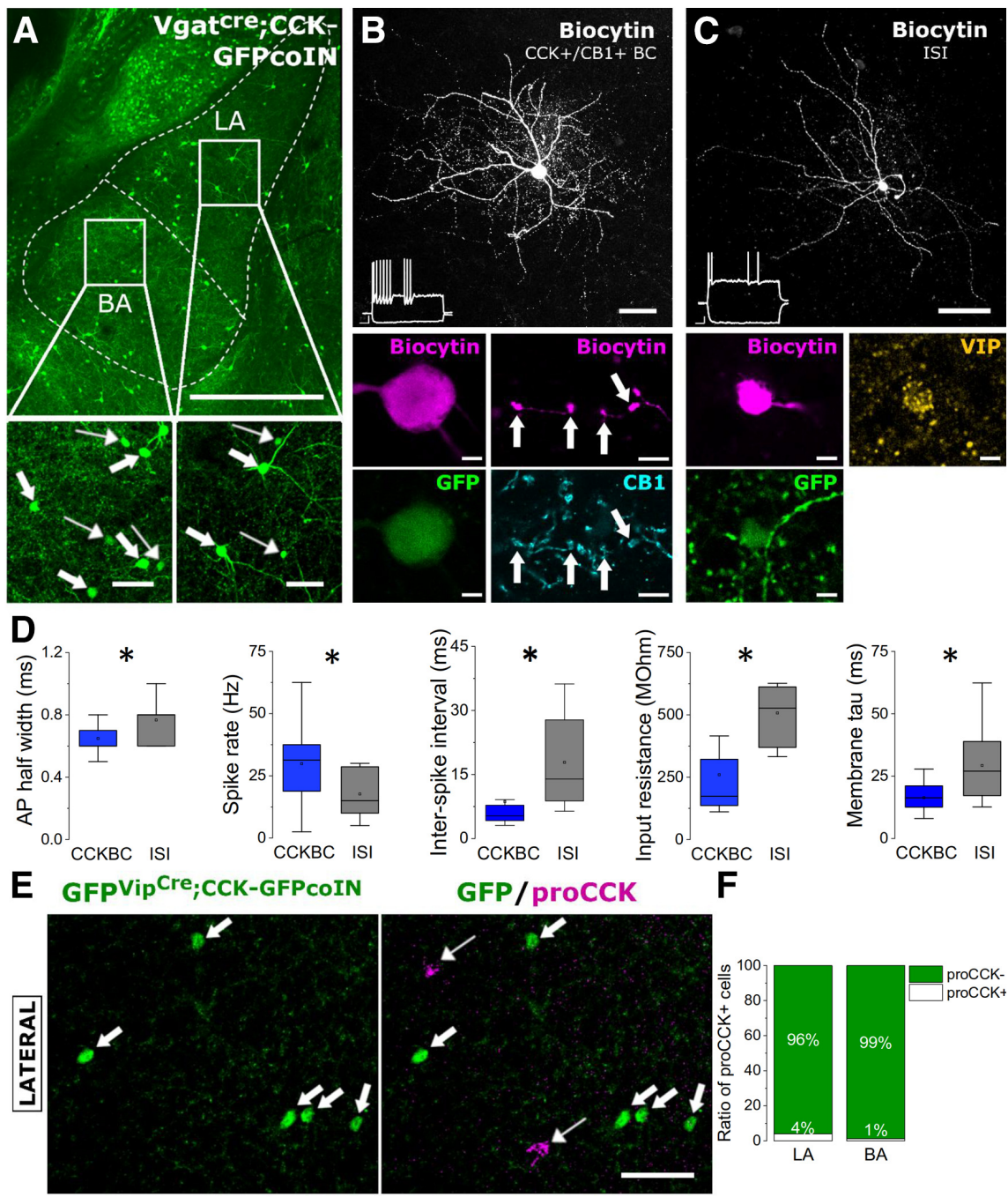

GFP/proCCK
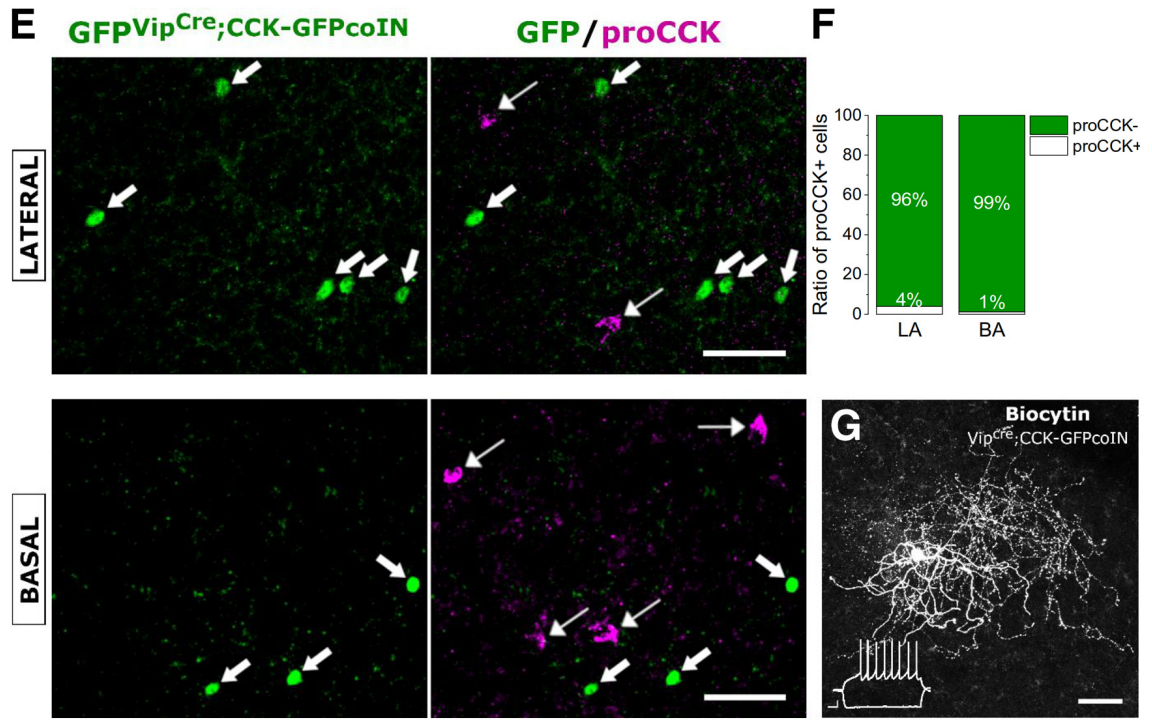

Figure 4. Characterization of interneurons expressing GFP in the amygdala of Vgat ${ }^{\mathrm{Cre}}$;CCK-GFPcolN and Vip ${ }^{\text {Cre }}$;CCK-GFPcoIN mice. $\boldsymbol{A}$, In Vgat ${ }^{\text {Cre }}$;CCK-GFPcolN mice, GFP expression visualizes GABAergic cells with large (thick arrows) and small (thin arrows) somata in both amygdalar nuclei. Scale bars: large images, $500 \mu \mathrm{m}$; small images, $50 \mu \mathrm{m}$. $\boldsymbol{B}$, An example GFP-expressing interneuron with large soma recorded in an acute slice prepared from a Vgat ${ }^{\mathrm{Cre}}$;CCK-GFPcolN mouse. Scale bar, $50 \mu \mathrm{m}$. The interneuron was identified as $\mathrm{CCK}^{+} / \mathrm{CB}^{+}$basket cell $(\mathrm{BC})$ based on its firing pattern and the $\mathrm{CB} 1$ immunoreactivity in its axonal boutons (white arrows in small images). Scale bar, $5 \mu \mathrm{m}$. C, An example for a GFP-expressing interneuron with small soma. Scale bar, $50 \mu \mathrm{m}$. The interneuron was identified as interneuron-selective interneuron (ISI) based on its firing characteristics and VIP content in its soma. Scale bar, $5 \mu \mathrm{m}$. D, Differences in single-cell features between $\mathrm{CCK}{ }^{+} / \mathrm{CB}^{+}{ }^{+}$basket cells $(C C K B C)$ and interneuron-selective interneurons (ISI) obtained in vitro. ${ }^{*} p<0.05$, significant difference. Here and in Figure $9 E$, the mean (small open square), median (midline of the box), the interquartile range (box), and the 5\%/95\% values (whiskers) are shown on the charts. For data, see Table 7. $\boldsymbol{E}$, In the LA and BA of Vip ${ }^{\text {(re }}$;CCK-GFPcolN mice, GFP is expressed in interneurons with small somata (thin arrows) that are immunonegative for proCCK (thin arrows) $(\boldsymbol{F})$. Scale bar, $50 \mu \mathrm{m}$. $\mathbf{G}$, An example interneuron recorded and labeled in an amygdalar slice. Scale bar, $50 \mu \mathrm{m}$. Its voltage responses on current injections (inset) are typical for VIP ${ }^{+}$interneuron-selective interneurons. Scale bars of the firing patterns: $x=100 \mathrm{~ms}, y=10 \mathrm{mV}$.

interneurons in cortical structures, including the amygdala (Rhomberg et al., 2018; Krabbe et al., 2019). Therefore, we labeled VIP-expressing interneurons in Vip-Cre mice using a viral vector and visualized the $\mathrm{CR}$ content in neurons by 
Table 7. Single-cell properties of CCK-expressing GABAergic cell types in the LA and BA ${ }^{a}$

\begin{tabular}{|c|c|c|c|c|c|c|}
\hline Parameter & $\begin{array}{l}\text { CCKBC } \\
(n=25-27)\end{array}$ & ISI $(n=7$ or 8$)$ & $\begin{array}{l}\mathrm{VIP}+/ \mathrm{CCK}^{+} \mid \mathrm{SI} \\
(n=5)\end{array}$ & $\begin{array}{l}\text { Kruskal- } \\
\text { Wallis ANOVA }\end{array}$ & $\begin{array}{l}\text { CCK BC vs ISI } \\
\text { (Mann-Whitney U test) }\end{array}$ & $\begin{array}{l}\text { ISI vs VIP }{ }^{+} / \mathrm{CCK}^{+} \\
\text {(Mann-Whitney } U \text { test) }\end{array}$ \\
\hline AP half-width (ms) & $0.6(0.6,0.7)$ & $0.8(0.6,0.8)$ & $0.7(0.7,0.9)$ & $0.036^{*}$ & $0.037^{* *}$ & 0.84 \\
\hline Spike rate $(\mathrm{Hz})$ & $31.3(18.8,37.5)$ & $15(10,28.6)$ & $13.8(11.3,22.5)$ & $0.049^{*}$ & $0.035^{* *}$ & 1 \\
\hline ISI between the first two spikes (ms) & $5.3(4.2,7.8)$ & $13.95(8.8,27.8)$ & $22.1(12.8,25.7)$ & $0.002^{*}$ & $0.005^{* *}$ & 0.93 \\
\hline ISI between the last two spikes (ms) & $26.85(22.6,32.8)$ & $34.85(5,65.9)$ & $39.5(33.6,46.5)$ & 0.30 & & \\
\hline Accommodation ratio & $4.89(3.92,6.58)$ & $7.95(2.76,14.8)$ & $3.09(1.81,5.6)$ & 0.28 & & \\
\hline Membrane capacitance (pF) & $74.32(51.19,84.8)$ & $46.52(39.05,56.71)$ & $48.62(36.73,133.405)$ & 0.097 & & \\
\hline Relative sag amplitude & $0.14(0.06,0.24)$ & $0.09(0.06,0.16)$ & $0.11(0.07,0.14)$ & 0.402 & & \\
\hline
\end{tabular}

${ }^{a}$ Data are median (first and third quartiles). CCKBC (CCK and CB1-expressing basket cell) and ISI (interneuron-selective interneurons) were recorded in Vgat ${ }^{\text {Cre }} ;$ CCK-GFPcolN mice. VIP+/CCK ${ }^{+}$ISI (interneuron-selective interneurons) were recorded in Vip ${ }^{\text {Cre }}$;CCK-GFPcoIN mice. AP, Action potential; AHP, after hyperpolarization, ISI, interspike interval.

*Significant difference (Kruskal-Wallis ANOVA).

**Significant difference (Mann-Whitney U test).

${ }^{\dagger}$ There was a significant difference between $\mathrm{CCKBC}$ versus $\mathrm{VIP}^{+} / \mathrm{CCK}^{+}$interneurons.

A



VgatCre;CCK-GFPcoIN



D
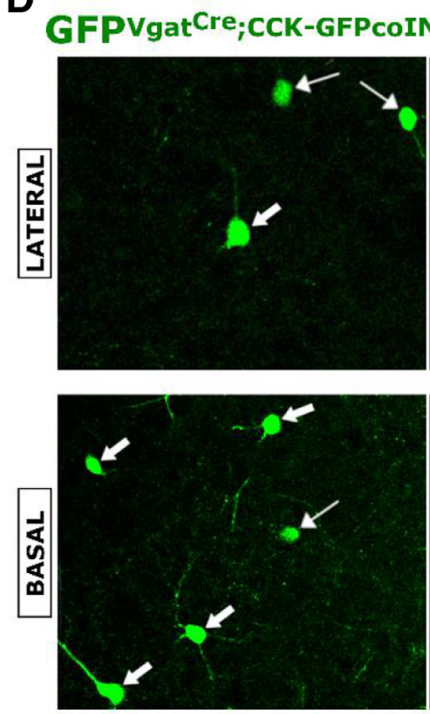

B

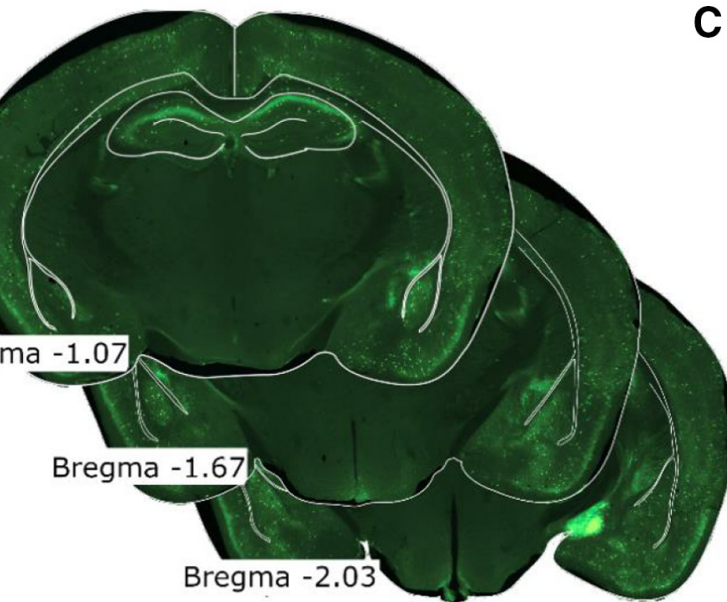

C

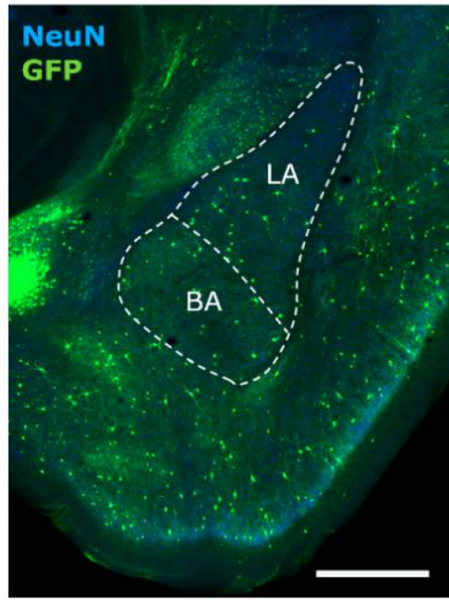

$\mathbf{E}$
$*$




LA

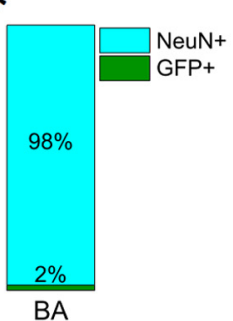

*

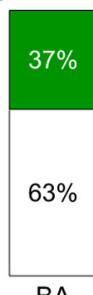

Figure 5. Number estimation for $\mathrm{CCK}^{+} / \mathrm{CB}^{+}{ }^{+}$basket cells using proCCK immunostaining in Vgat ${ }^{\mathrm{Cre}}$;CCK-GFPcolN mice. $\boldsymbol{A}$, Strategy to visualize GABAergic neurons expressing $\mathrm{CCK}$. $\boldsymbol{B}$, Representative images of GFP expression taken in a Vgat ${ }^{\mathrm{Cre}}$;CCK-GFPcolN mouse at the corresponding anterior-posterior coordinates (in mm) relative to bregma. $\boldsymbol{C}$, Representative example of the amygdalar region taken at a higher magnification. Scale bar, $500 \mu \mathrm{m}$. D, A large portion of GFP-labeled neurons that have large somata in Vgat ${ }^{\mathrm{Cre}}$;CCK-GFPcolN mice is immunoreactive for proCCK (thick arrows), whereas a minority of GFP-expressing interneurons, typically with small somata, lack immunopositivity for proCCK (thin arrows). A substantial number of proCCK ${ }^{+}$ GABAergic cells usually with large somata did not express GFP (open arrowheads). Scale bars, $50 \mu \mathrm{m}$. $\boldsymbol{E}$, The percentage of CCK ${ }^{+}$GABAergic cells in the LA and BA is different (top, ${ }^{*} p=0.0057$ ). In addition, there was a difference in the ratio of GFP ${ }^{+}$interneurons expressing procCK in the two amygdalar nuclei (bottom, $\left.{ }^{*} p=0.024\right)$. 

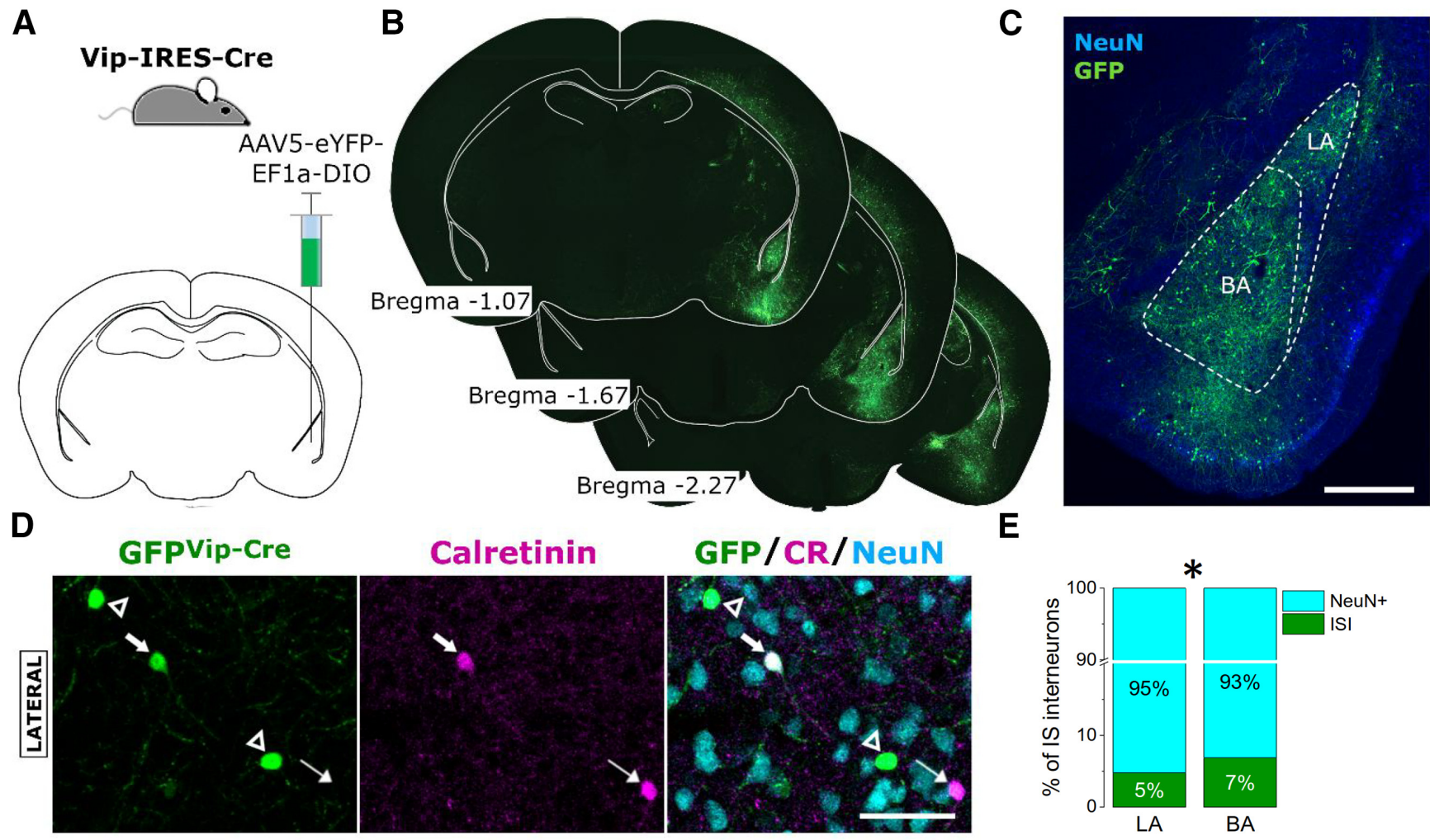

E
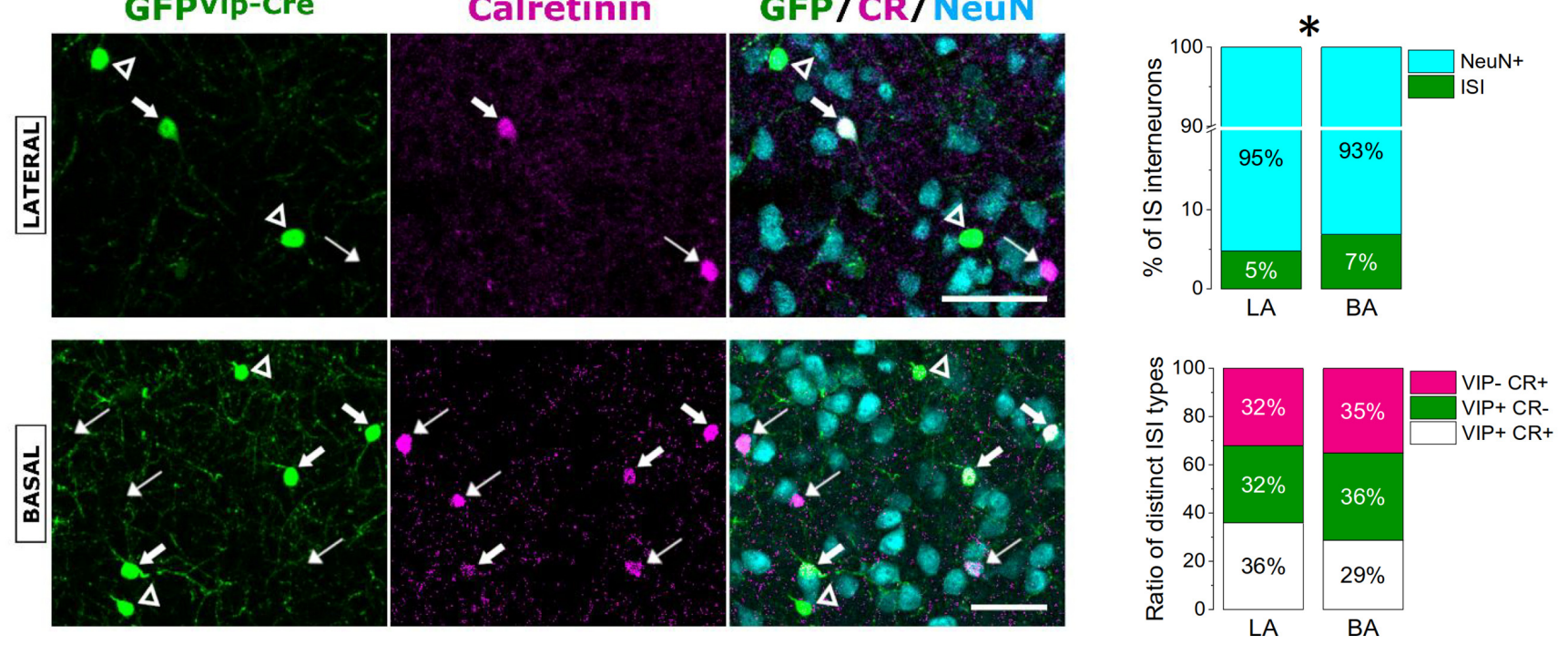

Figure 6. Interneuron-selective interneurons (ISI) in the LA and BA. $\boldsymbol{A}$, Schematic of the strategy for targeting VIP-expressing interneurons in the amygdala. $\boldsymbol{B}$, Representative images of GFP expression after virus transfection taken at the corresponding anterior-posterior coordinates (in $\mathrm{mm}$ ) relative to bregma. $C$, Representative example of the amygdalar region taken at a higher magnification. Scale bar, $500 \mu \mathrm{m}$. D, A portion of GFP-labeled neurons in Vip-Cre mice contains CR (thick arrows) or lacks immunopositivity for this $\mathrm{Ca}^{2+}$ binding protein (open arrowheads), but there are also (R-immunoreactive somata that do not contain GFP (thin arrows). All labeled interneurons had small somata regardless of their neurochemical content. Scale bars, $50 \mu \mathrm{m}$. $\boldsymbol{E}$, The percentage of interneuron-selective interneurons in the $L A$ and $B A$ differed (top, $\left.{ }^{*} p=0.0013\right)$. On the other hand, the ratios of the three neurochemically distinct ISI types $\left(V I P^{+} C R^{+}\right.$, $\mathrm{VIP}^{+}\left(\mathrm{R}^{-}\right.$, and $\mathrm{VIP}^{-}\left(\mathrm{R}^{+}\right)$were comparable in the two nuclei (bottom).

immunostaining (Fig. 6A-D). Our results show that interneuronselective interneurons, including $\mathrm{VIP}^{+} / \mathrm{CR}^{+}, \mathrm{VIP}^{+} / \mathrm{CR}^{-}$, and $\mathrm{VIP}^{-} / \mathrm{CR}^{+}$subtypes, gave rise to a large portion of inhibitory cells (Fig. 6E; Table 6). The ratio of interneuron-selective interneurons was significantly different between the two amygdalar nuclei (Table 6). In the LA, $35.9 \pm 5.1 \%$ of interneuron-selective interneurons expressed both VIP and CR, 31.9 $\pm 4.5 \%$ expressed only VIP, and $32.1 \pm 4.7 \%$ contained CR only. In the BA, $28.7 \pm 3.2 \%$ showed both VIP and CR labeling, $36.2 \pm 3.5 \%$ was labeled only for VIP, and $35.1 \pm 2.8 \%$ was immunolabeled only for CR (Fig. 6E). The fraction of the three interneuron-selective interneuron subtypes was comparable in both amygdalar nuclei $(p>0.22)$. These results show that $\mathrm{VIP}^{+}$and/or $\mathrm{CR}^{+}$interneuron-selective interneurons form the largest portion of GABAergic cell population in the LA and BA (see Fig. 11).

\section{$\mathrm{SST}^{+}$inhibitory cells}

In the mouse BLA, SST is present in a significant number of GABAergic cells; however, their postsynaptic targets, morphologic appearance, and single-cell features are mostly unexplored.
Therefore, we first examined the postsynaptic target distribution of SST-expressing axon terminals. We labeled SST-expressing inhibitory cells in Sst-Cre mice using a viral vector, and then the sections containing the amygdala region were immunostained for a voltagegated potassium channel Kv2.1, which visualizes the somata of amygdalar principal neurons (Vereczki et al., 2016). By counting the number of EYFP-expressing boutons that formed close appositions with the Kv2.1-immunoreactive somata, we observed that a very few of SST-expressing boutons target this membrane compartment of principal neurons either in the LA or BA (LA: 1\%, $n=667$ boutons; BA: $1.8 \%, n=1388$ boutons, $n=2$ mice). These results suggest that SST-containing boutons preferentially innervate the dendrites of neurons in mice similarly to that found in rats (Muller et al., 2007). To reveal the targets of SST-expressing axon endings and their occurrence along the dendritic tree of principal neurons, we intracellularly labeled single neurons in the LA and BA in acute slices that were prepared from mice where EYFP was expressed in SST-containing GABAergic cells. Using double immunostaining, we found that EYFP-expressing boutons that formed close appositions with the intracellularly labeled principal cells were evenly 


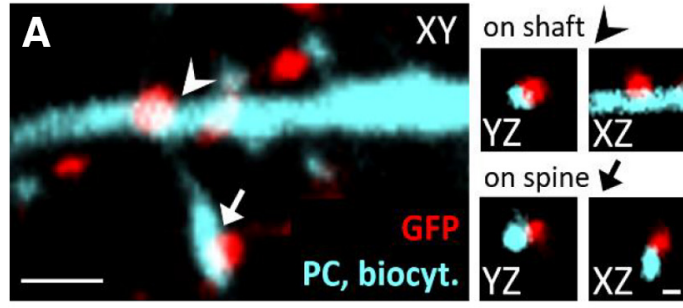

B

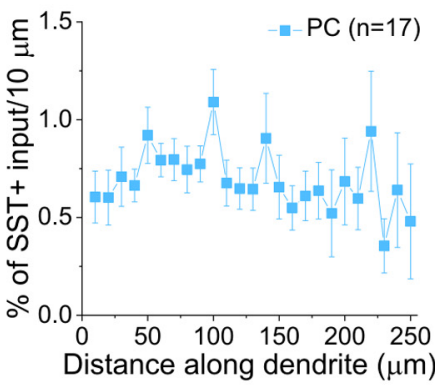

D

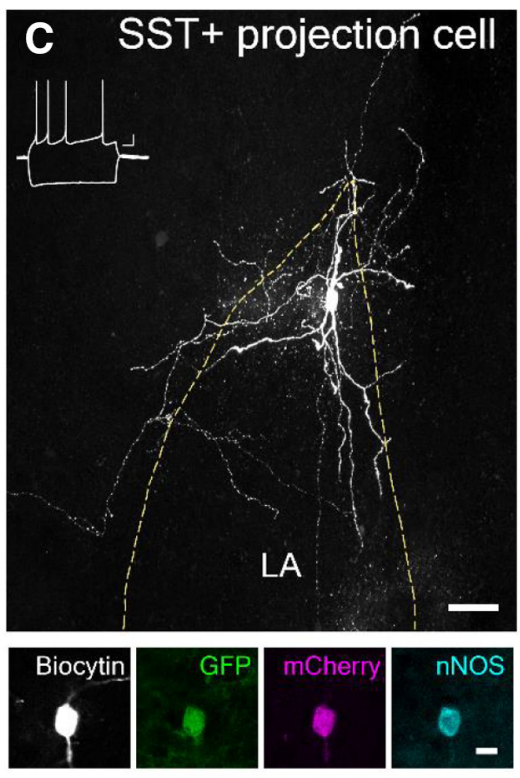

E SST+ projection cells

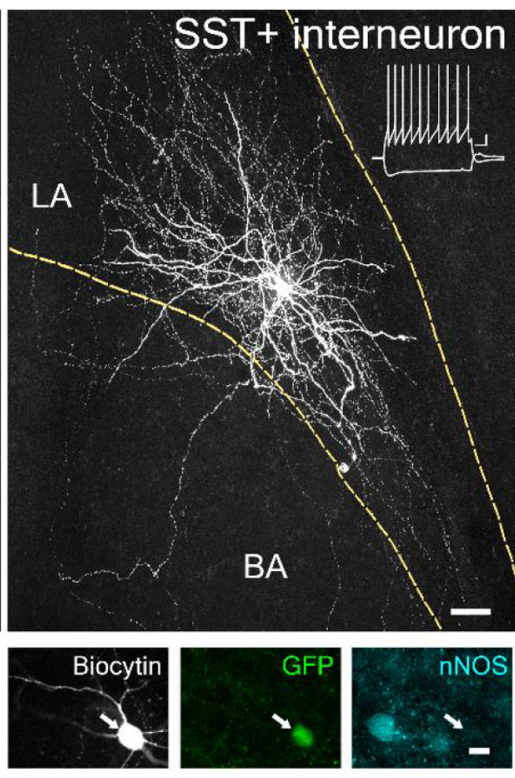

SST+ interneurons

$\square$ nNOS $+\square$ nNOS-SST+ cell projecting to entorhinal cortex $\Delta$ nNOS $+\triangle \mathrm{nNOS}-\mathrm{SST}+$ cell projecting to basal forebrain nNOS+O NNOS-SST+ inhibitory cell showing accomodating firing

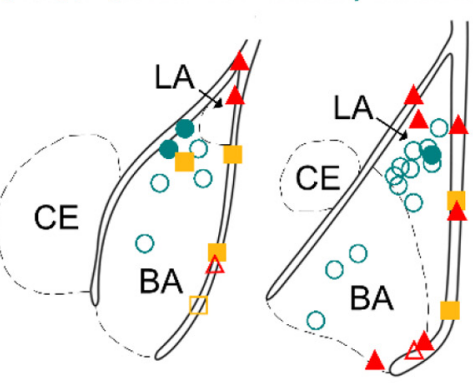

Bregma $-1.07 \mathrm{~mm}$

Bregma $-1.67 \mathrm{~mm}$

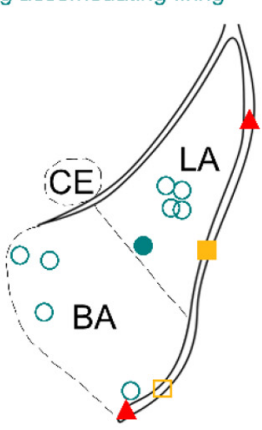

Bregma $-2.03 \mathrm{~mm}$
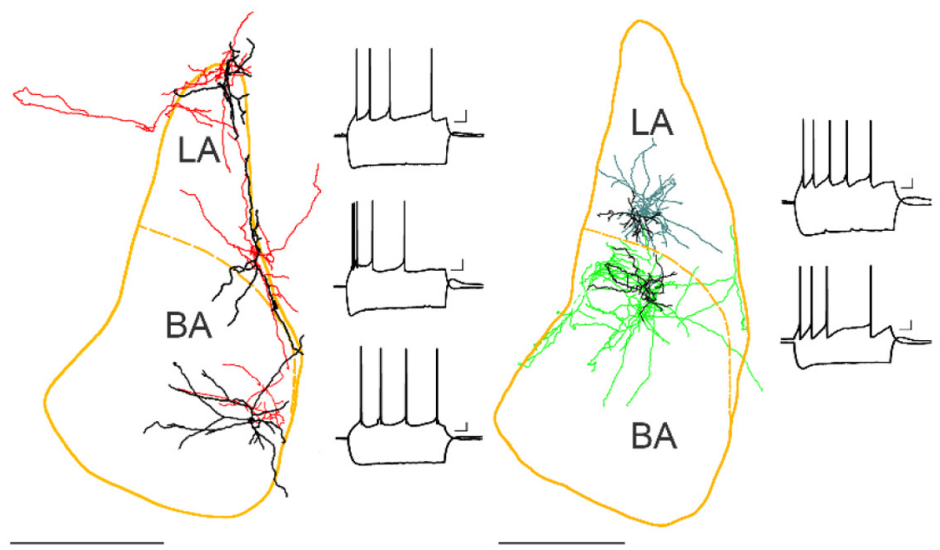

$\mathbf{F}$
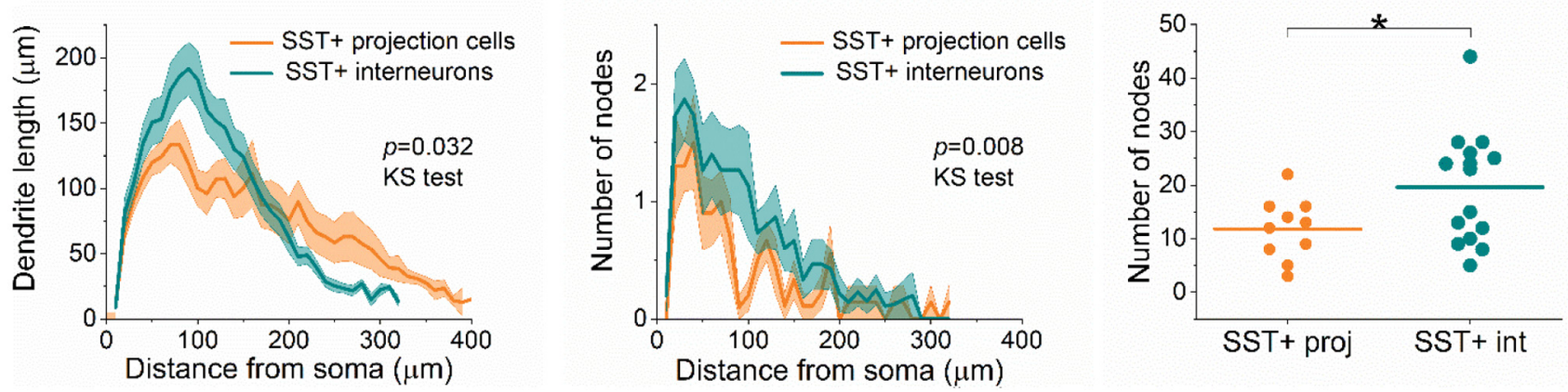

Figure 7. Characterization of GABAergic cells expressing SST in Sst-Cre mice. A, GFP ${ }^{+}$boutons labeled in the LA and BA using a viral strategy in Sst-Cre mice form close appositions with a dendritic shaft (arrowhead) and spine (arrow) of an intracellularly labeled amygdalar principal cell (PC). Scale bars: large images, $4 \mu \mathrm{m}$; small images, $1 \mu \mathrm{m} . \boldsymbol{B}^{\text {, Left, SST }}{ }^{+}$inputs evenly covered the dendritic tree of principal cells (8 LA and 9 BA PCS). Right, The majority of SST ${ }^{+}$boutons $(n=1493)$ target dendritic shafts of amygdalar principal cells. C, Two examples of biocytinfilled SST ${ }^{+}$GABAergic cells recorded in acute slices. SST ${ }^{+}$projection cells were labeled using an intersectional strategy by injecting retroAAV-mCherry-Flpo into the basal forebrain or entorhinal cortex and AAV-C(on)/F(on)-EYFF into the amygdala region. SST ${ }^{+}$interneurons were visualized on injection of AAV-DIO-EYFP into the BLA. Both SST ${ }^{+}$projection cells and interneurons showed accommodation in their spiking and displayed a sag in their voltage responses on negative step current injection (insets). In SST ${ }^{+}$projection cells, nNOS was typically present, whereas SST ${ }^{+}$ interneurons were immunonegative for this enzyme. Scale bars: large images, $50 \mu \mathrm{m}$; small images, $10 \mu \mathrm{m}$. D, Distribution of SST ${ }^{+}$inhibitory cells recorded in amygdalar slices. Each symbol represents the location of the cell body. $\boldsymbol{E}$, Neurolucida reconstruction of three SST ${ }^{+}$inhibitory cells projecting to the basal forebrain and two SST ${ }^{+}$interneurons (black represents dendrites; color represents axons) and the corresponding voltage responses on intracellular step current injections. Scale bar, $500 \mu \mathrm{m}$. The elongated and less ramified dendrites of projection cells, and more branched axons of interneurons, and also the similar voltage responses of both types of SST ${ }^{+}$inhibitory cells on step current injections $(x=100 \mathrm{~ms}, y=10 \mathrm{mV})$. $\boldsymbol{F}$, Comparison of the structure of the dendritic trees of SST ${ }^{+}$projection cells $(n=10)$ and interneurons $(n=15)$ using Sholl analysis. Dendritic length (left) and the number of nodes (center) as a function of distance from the soma are significantly different. Solid line indicates mean. Dashed line indicates SEM. Whereas the total dendritic length is comparable for the two SST ${ }^{+}$inhibitory cell types, the total number of nodes is significantly higher for $\mathrm{SST}^{+}$interneurons $\left({ }^{*} p=0.043\right)$. Dots represent number of nodes for individual neurons. Lines indicate the mean. 
Table 8. Single-cell properties of SST-expressing GABAergic cell types in the LA and BA

\begin{tabular}{lccc}
\hline \multicolumn{1}{c}{ Parameter } & SST $^{+}$interneurons $(n=17-24)$ & SST $^{+}$GABAergic projection cells $(n=15-20)$ & Mann-Whitney $U$ test $(p)$ \\
\hline AP half-width (ms) & $0.7(0.6,0.8)$ & $0.8(0.7,0.8)$ & 0.16 \\
Spike rate (Hz) & $45(37.5,51.3)$ & $55(32.5,72.5)$ & 0.37 \\
AHP 50\% decay (ms) & $34.6(9.2,65.8)$ & $27.6(13.5,42.7)$ & 0.72 \\
ISI between the first two spikes (ms) & $9.2(7.9,11.85)$ & $7.6(6.35,10.3)$ & 0.17 \\
ISI between the last two spikes (ms) & $28.2(21.55,33.35)$ & $26.75(16.3,34.1)$ & $2.86(2.16,4.48)$ \\
Accommodation ratio & $2.98(1.91,4.29)$ & $279.3(196.6,388.3)$ & 0.65 \\
Input resistance (MOhm) & $252.8(219.9,362.6)$ & $20.8(15.23,25.7)$ & 0.93 \\
Membrane time constant (ms) & $24.75(20.81,33.4)$ & $71.5(55.5,93.8)$ & 0.97 \\
Membrane capacitance (pF) & $93.3(76.7,121.2)$ & $0.177(0.125,0.399)$ & 0.053 \\
Relative sag amplitude & $0.28(0.134,0.427)$ & $62.8(49.4,99.4)$ & $0.014^{*}$ \\
Sag delay (ms) & $84.6(62.3,99.5)$ & & 0.4 \\
\hline
\end{tabular}

${ }^{a}$ Data are median (first and third quartiles). AP, Action potential; AHP, after hyperpolarization, ISI, interspike interval.

*Significant difference.

distributed along their dendritic trees (Fig. 7A,B). LA $(n=8)$ and BA $(n=9)$ principal cells were similarly covered by $\mathrm{EYFP}^{+}$axon terminals $(p=0.28$, Kolmogorov-Smirnov test); therefore, these results were pooled (Fig. $7 B$ ). With a closer inspection, we observed that EYFP-expressing boutons overall targeted dendritic shaft more frequently than spines (Fig. 7B). In LA, 137 and 814 boutons contacted spines and dendritic shaft, respectively $(n=8$ principal cells, $12,176 \mu \mathrm{m}$ total dendritic length), whereas 131 boutons formed close appositions with spines and 411 boutons with shafts of BA principal cells ( $n=9,13,816 \mu \mathrm{m}$ total dendritic length). The ratio of boutons contacting shafts versus spines in the LA $(6.3 \pm 1.1)$ and BA $(4.3 \pm 0.8)$ was similar ( $p=0.16$, Mann Whitney $U$ test). The distribution of EYFP-expressing boutons targeting dendritic shaft or spines along the dendritic trees was not significantly different either $(p=0.16$ in the LA, and $p=0.08$ in the BA). Thus, our results confirmed that the vast majority of SST-containing axon terminals target the dendritic compartment of amygdalar principal cells (Muller et al., 2007; Wolff et al., 2014); consequently, these GABAergic cells are in a position to play a role in dendritic inhibition.

In the next set of investigations, our goal was to characterize the GABAergic cells giving rise to SST-containing boutons in the two examined amygdalar nuclei. Previous studies showed that SST is expressed at least in two types of GABAergic cells. One type innervates primarily the dendrites of principal cells, whereas the other type, somata of which are present often in the external capsule, projects to remote areas, including the basal forebrain and entorhinal cortex (McDonald et al., 2012; McDonald and Zaric, 2015). Yet, none of these inhibitory cell types has been examined in detail. To record from SST-expressing GABAergic projection cells, we applied intersectional strategy by injecting retroAAV-mCherry-Flpo viruses into the basal forebrain or entorhinal cortex of Sst-cre mice, and AAV-C(on)/F(on)-EYFP into the amygdala region. This approach revealed retrogradely labeled SST ${ }^{+}$cells in the BLA (as well as in surrounding areas) in green, some of which were recorded and filled with biocytin in acute slices (Fig. 7C). We sampled 28 and 16 GABAergic cells that projected to the basal forebrain or the entorhinal cortex, respectively. We included only those neurons in the analysis that had axon collaterals in the LA and/or BA (12 and $8 \mathrm{SST}^{+}$projection cells targeting the basal forebrain and entorhinal cortex, respectively); that is, these GABAergic projection cells were in the position to participate in amygdala function. As neither the features of dendritic arbors nor the single-cell characteristics were found to be different in inhibitory cells projecting to the basal forebrain or entorhinal cortex $(p>0.21)$, we pooled the two datasets. Previous findings indicated that $\mathrm{SST}^{+}$GABAergic projection neurons often express nNOS (Sik et al., 1994; He et al.,
2016); therefore, we tested the presence of this enzyme in the sampled neurons using immunostaining. Accordingly, the vast majority of SST ${ }^{+}$GABAergic projection neurons indeed showed immunoreactivity for $\mathrm{nNOS}$ ( $78 \%, n=18$ tested). In each group of $\mathrm{SST}^{+}$GABAergic projection cells, i.e. targeting the basal forebrain or the entorhinal cortex, 2 neurons lacking immunoreactivity for nNOS were found. These observations therefore imply that the presence of nNOS in $\mathrm{SST}^{+}$inhibitory cells may be a good tool to separate projection cells from those that are local interneurons.

Next, we aimed to compare the properties of these $\mathrm{SST}^{+}$projection cells with $\mathrm{SST}^{+}$interneurons. To this end, we randomly sampled green cells in acute slices that were prepared from the amygdala region of Sst-cre mice after viral labeling (Fig. 7C). A total of $31 \mathrm{EYFP}^{+}$neurons were recorded with sufficiently labeled dendritic and/or axonal arbors (17 in the LA and 14 in the BA). Of these green neurons, two were fast spiking basket cells (one of them showed immunopositivity for PV, whereas in the other case, the PV immunoreactivity could not be unequivocally determined) and one neurogliaform cell. These three neurons were excluded from further analyses. Using immunostaining, we tested the expression of nNOS in remaining $\mathrm{EYFP}^{+}$neurons and found that this enzyme was present only in a minority of randomly sampled SST ${ }^{+}$inhibitory cells $(15 \%, n=26 ; 2$ in the LA and 2 in the BA; Fig. 7D). As our results show that nNOS is often present in $\mathrm{SST}^{+}$GABAergic projection cells, we excluded these four $\mathrm{SST}^{+} / \mathrm{nNOS}^{+}$inhibitory cells from further comparisons because they might have been randomly sampled projection neurons. Thus, the restricted group of $\mathrm{SST}^{+}$interneurons was composed of 13 and 11 cells in the LA and BA, respectively. As the single-cell features of $\mathrm{SST}^{+}$interneurons located in the $\mathrm{LA}$ and BA were similar $(p>0.2)$, the results were pooled and compared with those obtained for $\mathrm{SST}^{+}$GABAergic projection cells. We found that all but one parameter investigated were similar in the two types of SST ${ }^{+}$inhibitory cells (Fig. 7C,E; Table 8).

During the inspection of intracellularly labeled $\mathrm{SST}^{+}$inhibitory cells, we noticed that projection cells often emitted elongated dendrites and had only a few axon collaterals in slices, whereas local interneurons had rather multipolar dendritic trees and dense axonal arborization (Fig. 7C,E). As the dendritic tree may be less impacted by slicing than axons, we compared only the features of dendrites in the two groups of SST ${ }^{+}$inhibitory cells. We found no difference in any parameters for $\mathrm{SST}^{+}$interneurons in the LA $(n=8)$ and BA $(n=7 ; p>0.2)$; therefore, the two datasets were pooled and compared with those obtained for $\mathrm{SST}^{+}$projection cells $(n=10)$. Although no difference was found in the total dendritic length between $\mathrm{SST}^{+}$projection cells $(2467 \pm 434 \mu \mathrm{m}, n=10)$ and interneurons $(2695 \pm 234 \mu \mathrm{m}, n=$ 
A

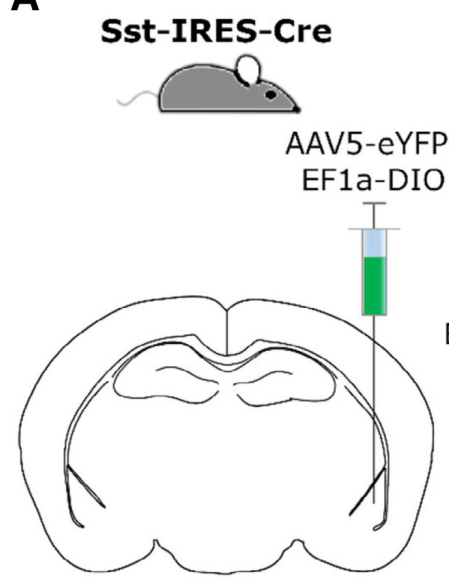

B

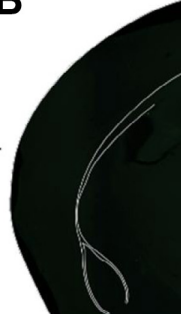

C

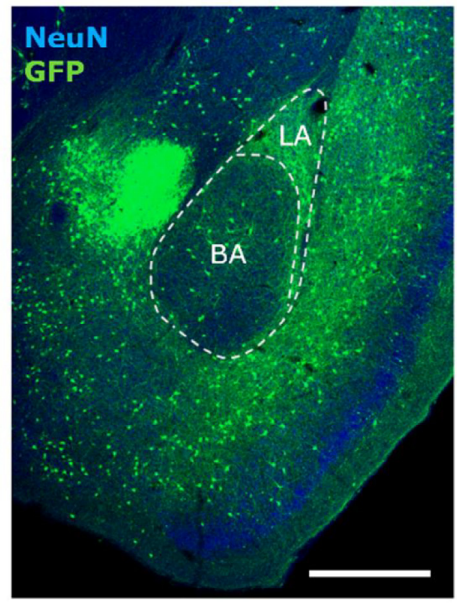

D
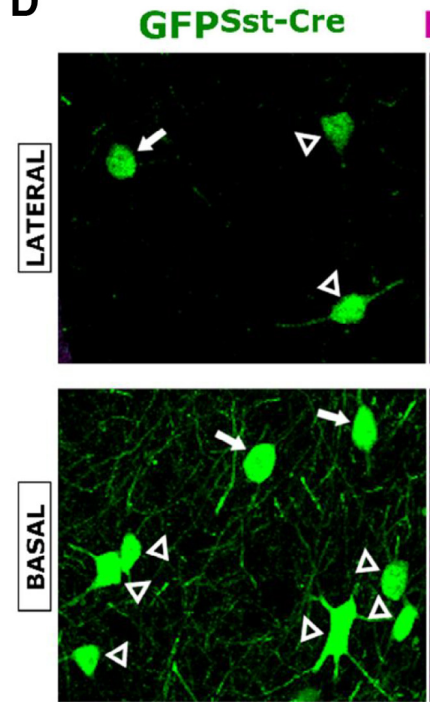

Nitric oxide synth. GFP/NOS/NeuN
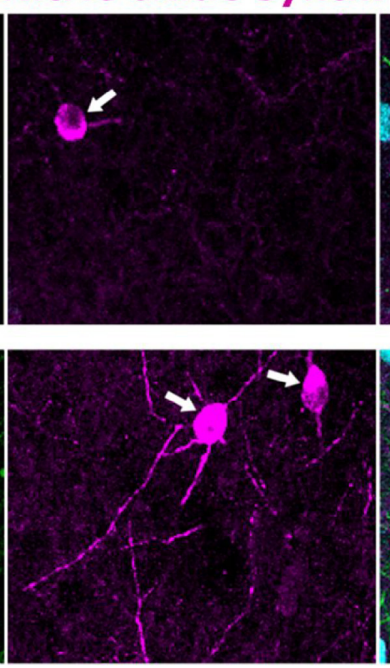
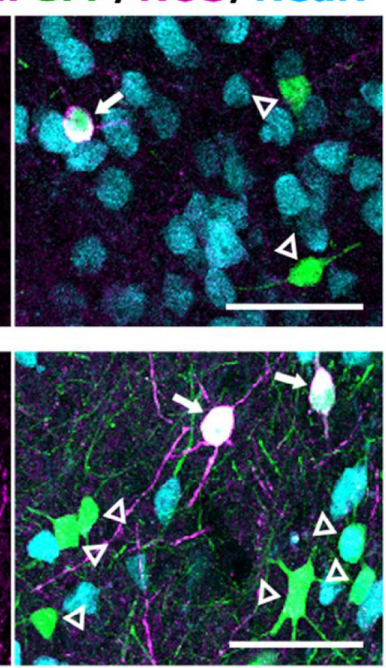

E

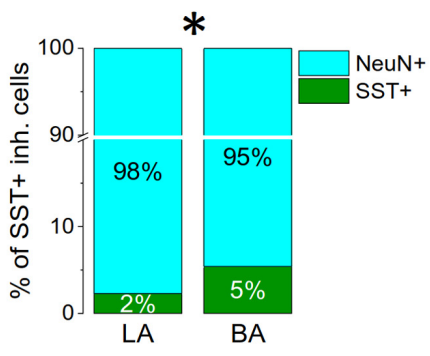

\#

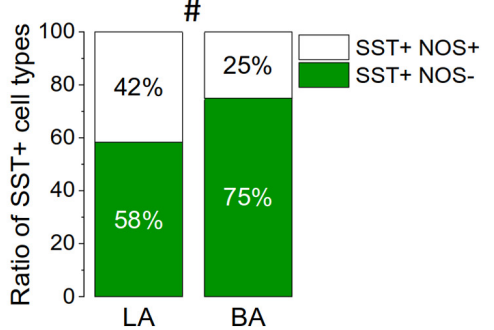

Figure 8. SST-expressing GABAergic cells in the LA and BA. $\boldsymbol{A}$, Schematic of the strategy for targeting SST-expressing GABAergic cells in the amygdala. $\boldsymbol{B}$, Representative images of GFP expression after virus transfection taken at the corresponding anterior-posterior coordinates (in $\mathrm{mm}$ ) relative to bregma. $\boldsymbol{C}$, Representative example of the amygdalar region taken at a higher magnification. Scale bar, $500 \mu \mathrm{m}$. D, In the majority of GFP-labeled neurons in Sst-Cre mice, no immunoreactivity for NOS (open arrowheads) was observed, yet there were a number of viruslabeled neurons that showed immunopositivity for this enzyme (arrows) in both nuclei. Scale bars, $50 \mu \mathrm{m}$. $\boldsymbol{E}$, Both the percentage of SST ${ }^{+}$GABAergic cells (top) and the percentage of SST $^{+}$inhibitory cells that express NOS (bottom) were different between the two nuclei. ${ }^{*} p=0.0018 .{ }^{\#} p=0.043$.

$15, p=0.62)$, the structure of their dendritic trees was clearly different. Sholl analysis revealed that the dendritic branches of $\mathrm{SST}^{+}$projection neurons were longer and less ramified (Fig. $7 F$ ), which was also reflected in the total number of nodes $(11.8 \pm$ $1.8, n=10 \mathrm{SST}^{+}$projection cells; 19.6 $\pm 2.7, n=15 \mathrm{SST}^{+}$interneurons; $p=0.043$ ). These results show that the two groups of $\mathrm{SST}^{+}$inhibitory cells display distinct morphology.

In the last set of experiments, we attempted to estimate the ratio of $\mathrm{SST}^{+}$GABAergic cells by labeling them in Sst-Cre mice using a viral vector (Fig. 8A-E; Table 6). We found that the fraction of $\mathrm{SST}^{+}$inhibitory cells differed significantly in the two amygdalar nuclei (Table 6). As two interneurons with a fast spiking phenotype were found among randomly sampled $\mathrm{SST}^{+}$inhibitory cells, we checked the colocalization of PV and SST in the population of GABAergic cells: we found a negligible presence of this $\mathrm{Ca}^{2+}$ binding protein in $\mathrm{SST}^{+}$inhibitory cells (LA: $1.3 \%, n=77$; BA: $1.6 \%, n=185, n=3$ mice). Finally, we assessed the ratio of $\mathrm{SST}^{+}$interneurons and $\mathrm{SST}^{+}$GABAergic cells with long-range projections in virus-labeled cells in Sst-Cre mice using immunostaining against nNOS (Fig. $8 D$ ). We observed that a considerable fraction of GFP-expressing $\mathrm{SST}^{+}$neurons showed immunolabeling for $\mathrm{nNOS}^{+}$(LA: 41.6\%; BA: $25 \%$ ), a ratio that was significantly different in the LA and BA $(p=0.043$; Fig. $8 E$; Table 6). These data indicate, in line with observations obtained in other cortical areas, that dendrite-targeting $\mathrm{SST}^{+}$ interneurons are more abundant than GABAergic projection cells expressing SST.

\section{$\mathrm{NPY}^{+}$neurogliaform cells}

In the subsequent investigation, we aimed to estimate the fraction of neurogliaform cells in the two amygdalar nuclei. As NPY has been shown to be a characteristic marker for the vast majority, if not for all, neurogliaform cells in cortical regions (Armstrong et al., 2012; Mańko et al., 2012; Paul et al., 2017), we used Npy-Cre mice to label these GABAergic neurons in the amygdala by injecting viruses carrying EYFP. We found that the vast majority of labeled neurons in Npy-Cre mice had indeed morphologic features typical for GABAergic neurons, but there were some labeled neurons with clear principal cell appearance. In line with this later notion, there was a considerable axonal projection in the contralateral BA in unilaterally injected NpyCre mice, axon collaterals that were decorated with boutons 

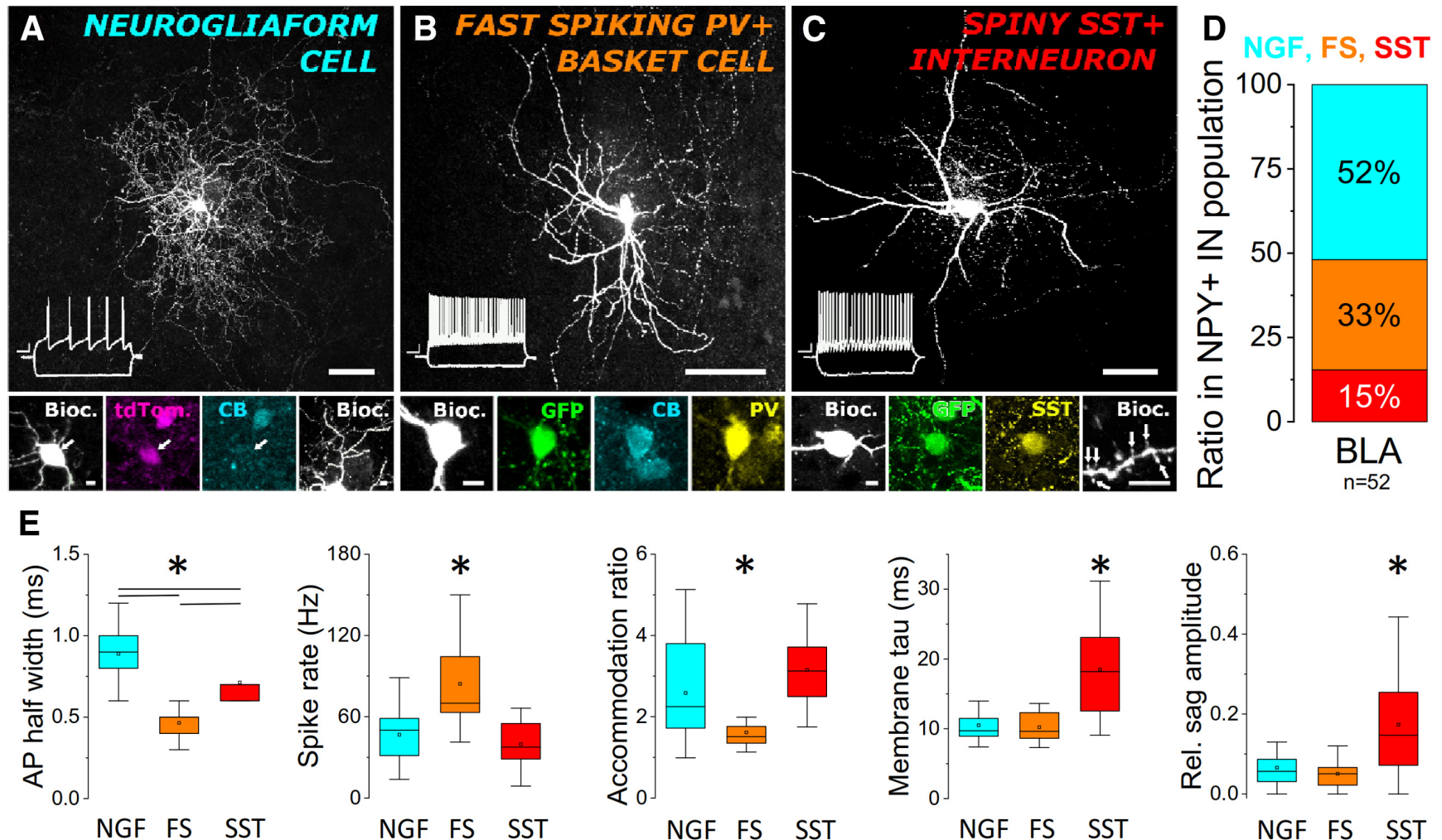

Figure 9. Three distinct inhibitory cell types express NPY in the amygdala. $\boldsymbol{A}$, In amygdalar slices prepared from offspring of virus-injected Npy ${ }^{\mathrm{Cre}} ;$;lx $5 / 6^{\mathrm{Flp}}$ mice or Npy-Cre $\mathrm{x}$ Ai 14 mice, the majority of recorded neurons had neurogliaform cell (NGF) morphology: a dense local axon arborization; short, frequently ramified dendrites (see small images below), a late-spiking phenotype (inset) and lacked $\mathrm{CB}$ content. $\boldsymbol{B}$, Another large group of $\mathrm{NPY}^{+}$interneurons showed a fast spiking phenotype (inset) and was immunoreactive for PV, and often for $\mathrm{CB}$, which is typical for $\mathrm{PV}^{+}$basket cells. $\mathrm{C}$, Inhibitory cells in the smallest group of $\mathrm{NPY}^{+}$neurons had sparsely spiny dendrites (white arrows point to spines in the small image) and showed immunopositivity for SST. Firing of these interneurons showed accommodation and sag in their voltage responses upon negative step current injection (inset). Scale bars: large images, $50 \mu \mathrm{m}$; small images, $5 \mu \mathrm{m}$. Scale bars of the firing patterns: $x=100 \mathrm{~ms}, y=10 \mathrm{mV}$. Bioc., biocytin. $\boldsymbol{D}$, Ratio of the morphologically, neurochemically, and electrophysiologically different NPY ${ }^{+}$inhibitory cell types sampled in vitro. BLA here refers to LA and BA. $E$, Single-cell properties of the three distinct GABAergic cells types expressing NPY in the amygdala. *Significant difference. For data, see Table 9.

Table 9. Single-cell properties of the three NPY-expressing GABAergic cell types in the LA and BA

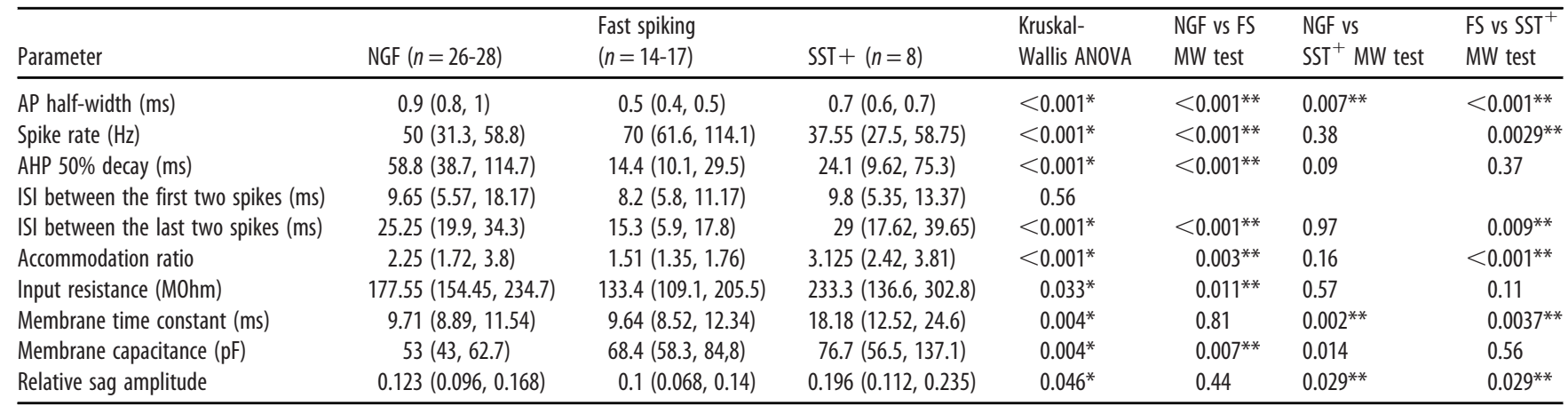

${ }^{a}$ Data are median (first and third quartiles). NGF, Neurogliaform cell; fast spiking, fast spiking $\mathrm{PV}^{+}$interneurons; SST $^{+}$, SST-immunoreactive interneurons; AP, action potential; AHP, after hyperpolarization, ISI, interspike interval.

*Significant difference (Kruskal-Wallis ANOVA).

**Significant difference (Mann-Whitney U test).

immunoreactive for VGluT1 (data not shown), a type of vesicular glutamate transporter expressed in amygdalar principal cells (Andrási et al., 2017). In addition, principal cells could be recorded, although infrequently, in offspring of Npy-Cre x Ai14 mice (see below).

Thus, to ensure that we study only $\mathrm{NPY}^{+}$GABAergic neurons in the amygdala, double-transgenic mice were generated by intercrossing Npy-Cre mice with Dlx5/6-Flpe mice that express Flp recombinase in the majority of GABAergic neurons in cortical structures (Miyoshi and Fishell, 2011). Then, we injected
INTRSECT viruses into the amygdalar region of $\mathrm{Npy}^{\mathrm{Cre}}$;Dlx5/ $6^{\text {Flp }}$ mice to transfect those GABAergic neurons with EYFP content that express both Cre and Flp recombinases. This approach resulted in no labeling in principal cells assessed by the lack of axonal projection in the contralateral BA and by sampling no principal cells in acute slice preparations.

To reveal the cell types that express NPY in the LA and BA, we performed whole-cell recordings in EYFP-expressing neurons in acute amygdalar slices that were prepared from AAV-injected $\mathrm{Npy}^{\mathrm{Cre}} ; \mathrm{Dlx} 5 / 6^{\mathrm{Flp}}$ mice or offspring of Npy-Cre $\mathrm{x}$ Ai14 mice. 


\section{A

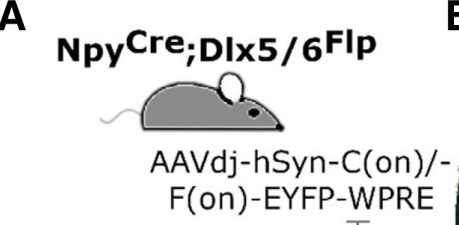

B
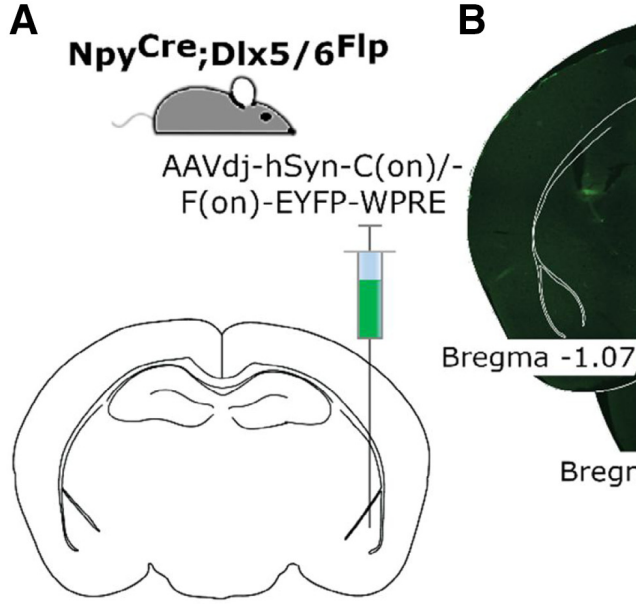

Bregma - 1.07
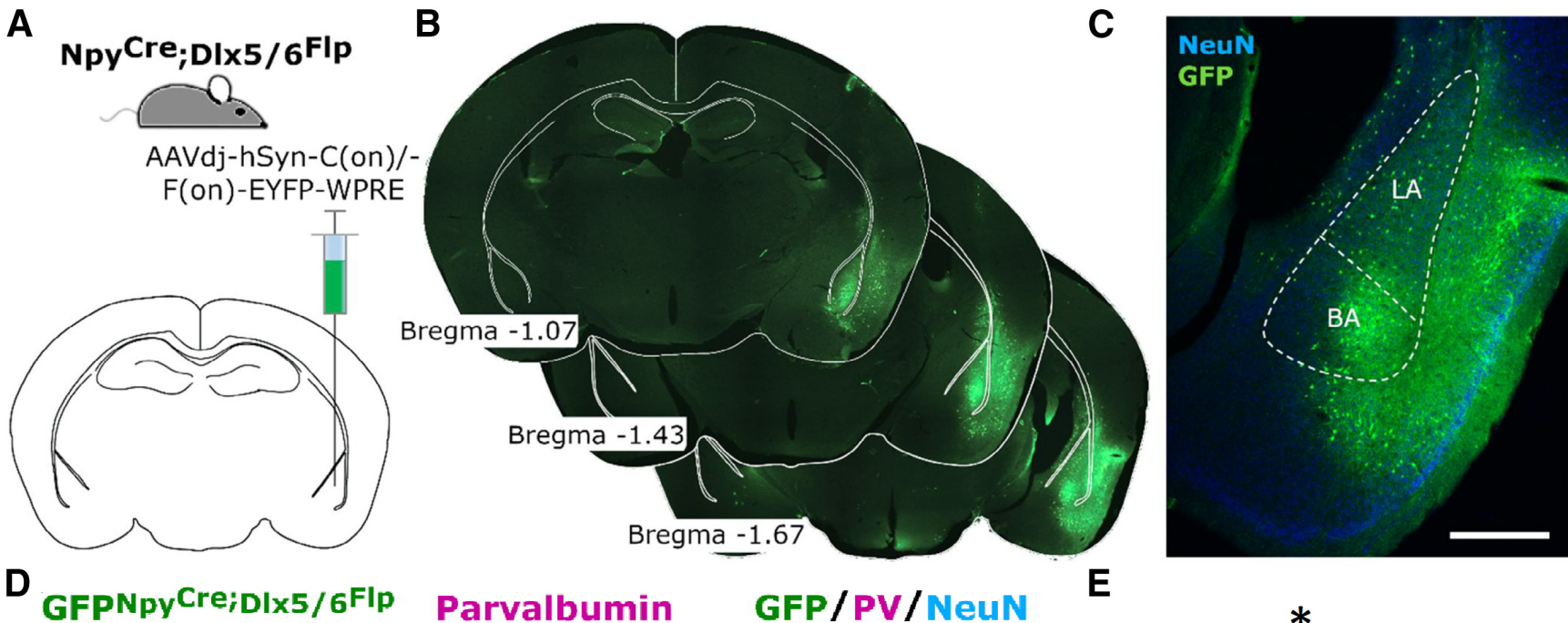

\section{Parvalbumin}

GFP/PV/NeuN
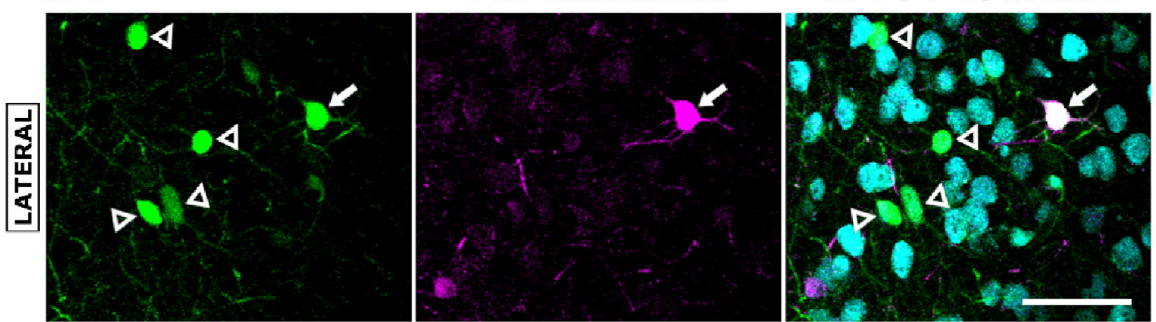

E
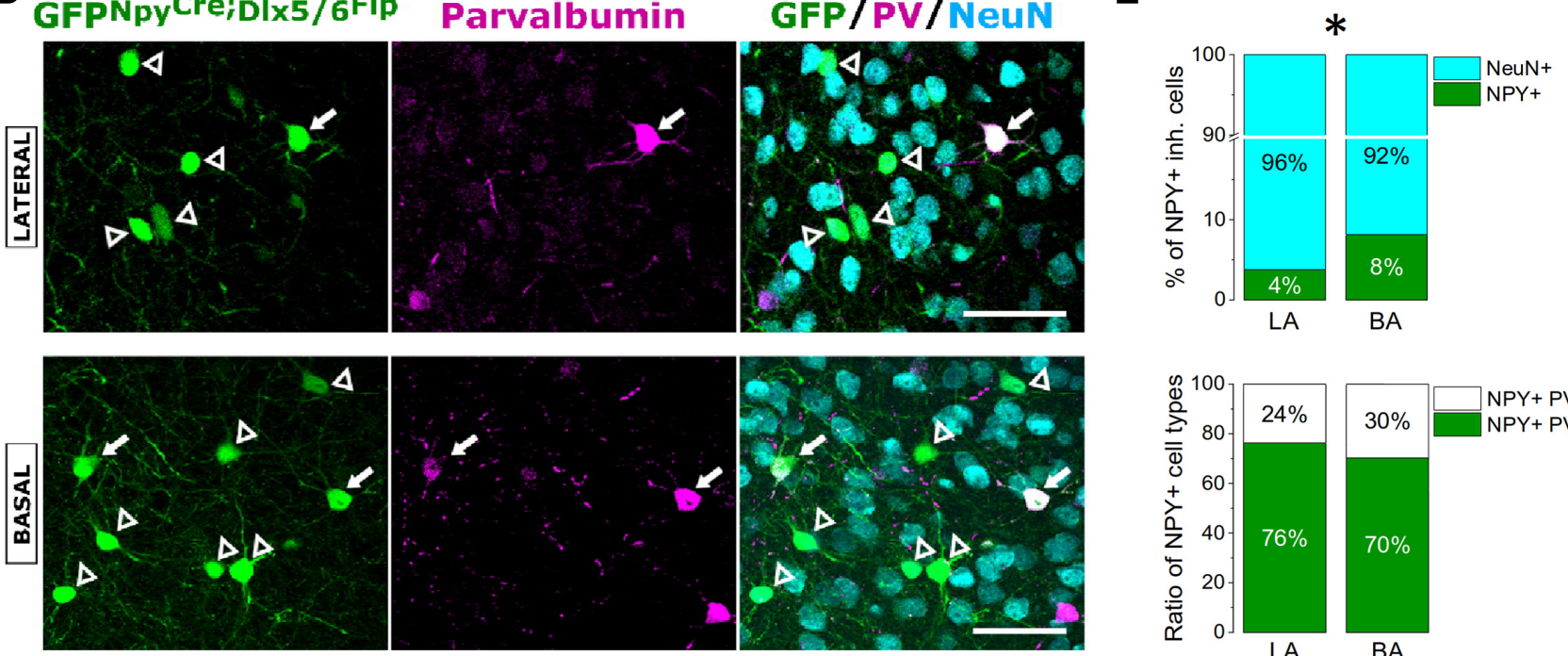

$\mathbf{F}$

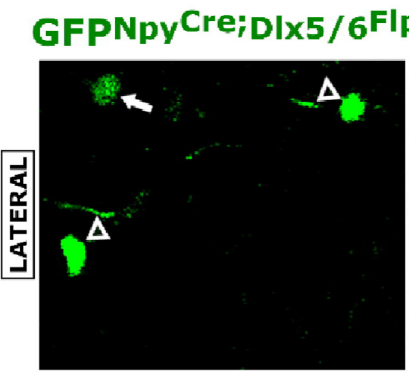

\section{Somatostatin}
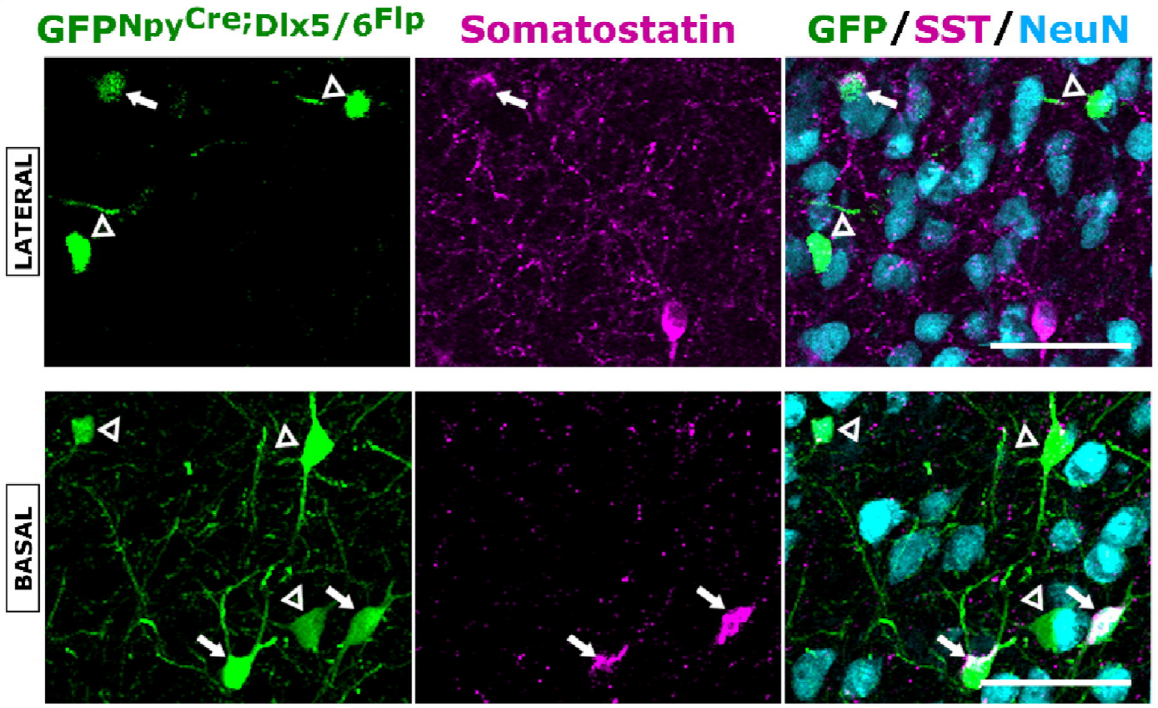

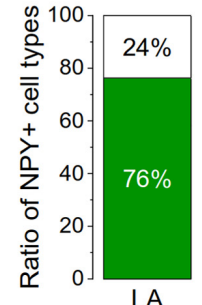

G

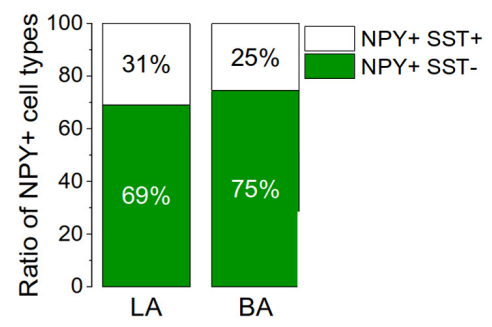

H

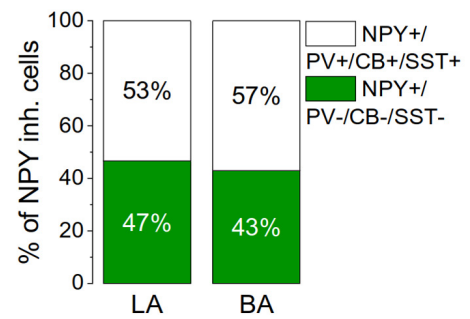

Figure 10. NPY-expressing GABAergic cells in the LA and BA. $\boldsymbol{A}$, Schematic of the strategy for targeting NPY-expressing interneurons in the amygdala. $\boldsymbol{B}$, Representative images of GFP expression after virus transfection taken at the corresponding anterior-posterior coordinates (in $\mathrm{mm}$ ) relative to bregma. $\boldsymbol{C}$, Representative example of the amygdalar region taken at a higher magnification. Scale bar, $500 \mu \mathrm{m}$. D, In Npy ${ }^{\mathrm{Cre}}$;Dlx5/6 ${ }^{\mathrm{Flp}}$ mice, a notable portion of GFP-labeled GABAergic cells expresses PV (arrows) in both nuclei. Open arrowheads indicate GFP ${ }^{+}$neurons lacking PV immunoreactivity. Scale bar, $50 \mu \mathrm{m}$. $\boldsymbol{E}$, The ratio of NPY ${ }^{+}$GABAergic cells in the LA and BA was significantly different (top, ${ }^{*} p<0.001$ ), but the ratio of NPY ${ }^{+}$inhibitory cells containing PV did not differ (bottom). $\boldsymbol{F}$, Another portion of NPY ${ }^{+}$GABAergic cells showed immunoreactivity for SST (arrows) in both nuclei. Open arrowheads indicate GFP ${ }^{+}$neurons lacking SST

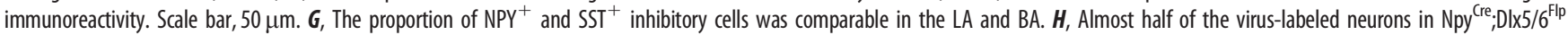
mice should represent the population of neurogliaform cells both in the LA and BA, assessed by lack of immunoreactivity in GFP-labeled interneurons for PV, CB, and SST. 
Based on the single-cell electrophysiological features, including the action potential halfwidth (measured at half the amplitude between the threshold and the peak voltage), maximum spiking rate, accommodation ratio, membrane time constant, and sag amplitude, three main GABAergic cell groups could be identified among randomly sampled neurons expressing reporter proteins (Fig. 9). The largest number of recorded neurons (52\%) were neurogliaform cells showing a typical late-spiking phenotype (Fig. 9A,D). The single-cell properties of these neurons could be characterized by wide action potentials, moderate spike rate with accommodation, fast membrane time constant, and no or minimal sag in their voltage responses on negative current injections (Fig. 9E; Table 9). Labeled interneurons in this group displayed characteristic morphologic features of neurogliaform cells, including short smooth dendrites that often ramified and dense local axonal arborization (Fig. 9A). Many of these interneurons showed weak immunoreactivity for nNOS (22 of 25 tested), but none for PV (0 of 9 tested), CB ( 0 of 25 tested), or SST ( 0 of 4 tested) (Fig. 9A). The second largest group of interneurons (33\%) showed a fast spiking phenotype (Fig. 9B,D). These interneurons had narrow spikes, the highest firing rate, no accommodation in spiking, fast membrane time constant, and no sag (Fig. 9E; Table 9). Spine-free dendrites and axon arborization of the interneurons in this category resembled the appearance typical for $\mathrm{PV}^{+}$ basket cells and axo-axonic cells (Vereczki et al., 2016). Immunostaining revealed that many of these $\mathrm{NPY}^{+}$interneurons were indeed immunoreactive for PV (5 of 7 tested) and for CB (3 of 6 tested) (Fig. 9B). Of 6 fast spiking interneurons tested, we observed SST immunoreactivity in 1 case. In addition, where only a part of the axon could be revealed, labeled boutons of this fast spiking $\mathrm{NPY}^{+}$interneuron formed close appositions with axon initial segments visualized by Ankyrin G staining, confirming that some of the axo-axonic cells can express NPY. The third group of recorded neurons (15\%) had relatively narrow spikes, showed accommodation in spiking, and had a relatively slow membrane time constant and a sag in their voltage responses on negative current injections (Fig. 9E; Table 9). Morphologic characteristics of these GABAergic cells were similar to those typical for $\mathrm{SST}^{+}$interneurons, including sparsely spiny dendrites and elongated soma. Indeed, all but one of the NPY ${ }^{+}$GABAergic cells in this group showed strong immunopositivity for SST (6 of 7 tested) (Fig. 9C). We have also recorded from an NPY ${ }^{+}$interneuron, which showed clear immunoreactivity for CB1 on its axon terminals and displayed a typical firing pattern of $\mathrm{CCK}^{+}$ basket cells. In addition to inhibitory cells, some principal cells were also recorded in offspring of Npy-Cre $\mathrm{x}$ Ail4 mice $(n=3)$, but not in $\mathrm{AAV}$-injected $\mathrm{Npy}{ }^{\mathrm{Cre}} ; \mathrm{Dlx} 5 / 6^{\mathrm{Flp}}$ mice. These results obtained in acute slices combined with immunocytochemical data suggest that the ratio of neurogliaform cells, $\mathrm{PV}^{+}$fast spiking interneurons, and $\mathrm{SST}^{+}$inhibitory cells visualized in $\mathrm{Npy}^{\mathrm{Cre}}$; Dlx $5 / 6^{\text {Flp }}$ mice by a viral vector can be assessed by their PV or SST content at the population level.

Before performing this estimation, we first determined the fraction of all NPY ${ }^{+}$inhibitory cells in the LA and BA (Fig. 10; Table 6). The ratio of $\mathrm{NPY}^{+}$inhibitory cells was significantly different in the two amygdalar nuclei (Table 6). To reveal the ratio of $\mathrm{NPY}^{+}$inhibitory cells that express PV or SST, we tested the neurochemical content of $\mathrm{GFP}^{+}$cells using immunostaining (Fig. 10D,F). We observed that a significant fraction $(\sim 25 \%)$ of these neurons was immunoreactive for PV (Fig. 10D,E; Table 6). In addition, a similarly large portion $(\sim 27 \%)$ of EYFP-expressing GABAergic neurons showed immunoreactivity against SST (Fig. $10 F, G$; Table 6). Thus, based on the immunostaining, approximately half of the $\mathrm{NPY}^{+}$GABAergic neurons $(\sim 45 \%$ in both amygdalar nuclei) was immunoreactive neither for PV nor for SST, a group of neurons that should correspond to neurogliaform cells. Although there is almost no overlap between PV and SST immunoreactivity in amygdalar inhibitory cells, it would be more accurate to estimate the ratio of $\mathrm{NPY}^{+}$neurons lacking PV and SST immunoreactivity in the same immunostained sections. Moreover, $\mathrm{CB}$, which was absent in in vitro labeled neurogliaform cells but is present in a large number of various types of GABAergic cells in the BLA (McDonald and Mascagni, 2001), may visualize additional inhibitory cell types, refining the ratio of neurogliaform cells even more. Therefore, we performed immunostaining against PV, SST, and CB in amygdalar sections of $\mathrm{Npy}^{\mathrm{Cre}} ; \mathrm{Dlx} 5 / 6^{\text {Flp }}$ mice in which EYFP expression visualized GABAergic cells. Using this approach, we found that neurogliaform cells may represent $\sim 45 \%$ of $\mathrm{NPY}^{+}$GABAergic cells expressing EYFP but lacking immunoreactivity for PV, SST, and CB (four sections/mouse, 3 mice) (Fig. 10G; Table 6). Thus, based on the observations that almost half of all $\mathrm{NPY}^{+} \mathrm{GABAergic}$ cells are neurogliaform cells, we calculated that these interneurons make up $1.8 \%$ and $3.5 \%$ of all neurons in the LA and BA, respectively.

The ratios of the major inhibitory cell categories are similar in the LA and BA

Finally, we calculated the fractions of the major GABAergic cell types within the investigated inhibitory cell groups in the two 
amygdalar nuclei. Our results show that these cell types constitute a comparable fraction of inhibitory neurons in the LA and BA (Fig. 11).

\section{Discussion}

In the mouse, we found that the number of neurons in the LA is significantly less than that found in the BA, in agreement with a recent study using molecular biological approaches (O'Leary et al., 2020). This observation is in contrast with findings reported in the rat, monkey, and human amygdala, where a similar or rather larger number of neurons were observed in the LA compared with the BA (Schumann and Amaral, 2005; Chareyron et al., 2011). The discrepancy between the ratios of neurons in the LA and BA reported in the mouse compared with previous studies investigating other mammals may reflect diversity across species. Alternatively, defining the BA borders may substantially differ among studies, which may explain the differences at least in part. In other studies, amygdalar nuclei, including the BA, were usually defined based on cytoarchitecture, whereas here we used VAchT immunostaining to objectively delineate the BA borders, an approach that may be easy to adopt in future studies.

The ratio of inhibitory cells in the LA and BA found in this study is similar to those estimated earlier in rat and monkey BLA (McDonald, 1992; McDonald and Augustine, 1993) and is in good agreement with the overall estimation of GABAergic cell number in other cortical structure (Gabbott and Somogyi, 1986; Beaulieu et al., 1992; Ren et al., 1992). At present, it is unclear the reason why the LA contains substantially less inhibitory cells, but one may speculate that this difference in neuronal composition supports distinct roles for the LA and BA in amygdala-related circuit operations (Janak and Tye, 2015; Manassero et al., 2018).

In addition to the number of GABAergic cells, we also attempted to assess the ratio of distinct inhibitory neuron types in the LA and BA. We took advantage of the fact that, in adult Pvalb-Cre, Sst-Cre, and Vip-Cre mice, viral labeling visualizes one or two GABAergic cell categories that can be separated by immunostaining. In Pvalb-Cre mice, fast spiking basket cells and axo-axonic cells could be distinguished based on the CB content (Bienvenu et al., 2012; Vereczki et al., 2016; Andrásiet al., 2017; Rovira-Esteban et al., 2019). We estimated that $17 \%$ and $20 \%$ of all GABAergic cells are $\mathrm{PV}^{+}$basket cells in the LA and BA, respectively. Similar ratio for this interneuron type was estimated in the hippocampus (Bezaire and Soltesz, 2013), whereas twice as many PV-expressing interneurons were found in the frontal, primary somatosensory and visual cortices (Xu et al., 2010). The large difference in the ratio in interneurons containing PV suggests that the convergence and divergence between these interneurons and their targets may follow distinct rules in different cortical areas.

One of our novel findings is the identification of axo-axonic cells lacking PV in the LA and BA. Importantly, axo-axonic cells expressing or lacking PV followed the same innervation strategy in both nuclei, confirming and expanding our previous observations (Veres et al., 2014). Based on our data, it is safe to predict that PV is absent in approximately one-third of all axo-axonic cells in the LA and BA. This ratio posits these two amygdalar nuclei between the hippocampus and PFC, as in the former structure only PV-containing axo-axonic cells have been found (Katsumaru et al., 1988), whereas in the latter the majority of these GABAergic interneurons lacks PV (X. Wang et al., 2019).

In this study, we used a novel transgenic mouse line, the BACCCK-GFPcoIN_sb, to visualize CCK-expressing GABAergic cells in the brain after intercrossing with Vgat-Cre. In offspring (i.e., Vgat $^{\text {Cre }}$;CCK-GFPcoIN mice), the majority of recorded interneurons were basket cells. We found that 7\%-9\% of all inhibitory cells in the $\mathrm{LA}$ and $\mathrm{BA}$ are $\mathrm{CCK}^{+} / \mathrm{CB}^{+}$basket cells, a ratio that is similar to that estimated in the hippocampus (Bezaire and Soltesz, 2013). Of note, in this novel transgenic mouse line, we have not sampled fast spiking cells or neurogliaform cells, interneuron types that could be often targeted in $\mathrm{Cck}^{\mathrm{Cre}} ; \mathrm{Dlx} 5 / 6^{\mathrm{Flp}}$ mice, in addition to $\mathrm{CCK}^{+} / \mathrm{CB}^{+}{ }^{+}$basket cells (Rovira-Esteban et al., 2019). These data suggest that the two strategies, the knock-in versus the use of BAC as a tool to generate transgenic lines, produce mice that express the Cre recombinase or fluorescent proteins in distinct populations of $\mathrm{CCK}^{+}$inhibitory cells, yet $\mathrm{CB} 1^{+}$basket cells are always affected, albeit with a different efficacy.

In Vip-Cre mice, interneuron-selective interneurons containing or lacking CR can be predominantly, if not exclusively, labeled using the method applied (Rhomberg et al., 2018; Krabbe et al., 2019). Based on earlier data obtained in the hippocampus (Acsády et al., 1996; Gulyas et al., 1996; Hájos et al., 1996), we hypothesized that $\mathrm{CR}^{+} / \mathrm{VIP}^{-}$interneurons also belong to the interneuron-selective interneuron group, although future work should confirm our assumption. One of our surprising findings was that interneuron-selective interneurons in the LA (38\%) and BA $(29 \%)$ are more abundant than in the hippocampus $(20 \%)$ (Bezaire and Soltesz, 2013) and neocortex (23\%-30\%) (Xu et al., 2010). Thus, our observation may imply that the massive regulatory potential of interneuron-selective interneurons over other GABAergic cells can play a central role in the control of various amygdala functions, as it has been shown recently for affective memory formation (Krabbe et al., 2019).

In this study, we provide the first detailed characterization of $\mathrm{SST}^{+}$GABAergic cells in the LA and BA. As in the hippocampus and neocortex (Katona et al., 1999; Y. Wang et al., 2004), SST ${ }^{+}$ inhibitory cells target predominantly the dendritic shaft and, to a lesser extent, the spines of principal cells. $\mathrm{SST}^{+}$GABAergic cells that project to the basal forebrain or entorhinal cortex (McDonald et al., 2012; McDonald and Zaric, 2015) were found to be immunopositive for nNOS. This enzyme content in $\mathrm{SST}^{+}$ GABAergic cells thus helped us to estimate the ratios of interneurons and projection neurons expressing SST in the LA and BA. We found a similar ratio for $\mathrm{SST}^{+}$GABAergic projection cells in the amygdala as it was reported in the hippocampus (5\%6\%) (Bezaire and Soltesz, 2013). However, this latter study estimated significantly less $\mathrm{SST}^{+}$interneurons in the hippocampus (4\%-5\%), than we found in the amygdala (10\%-16\%), or others in the neocortex (17\%-20\%) (Xu et al., 2010). Future studies should clarify the reason of this surprisingly low ratio of $\mathrm{SST}^{+}$ interneurons in the hippocampus.

NPY has been shown to be expressed often in neurogliaform cells (Fuentealba et al., 2010; Tricoire et al., 2010; Armstrong et al., 2012; Mańko et al., 2012; Perrenoud et al., 2013). In neocortical areas, $7 \%-10 \%$ of GABAergic cells were found to express NPY (Xu et al., 2010), whereas $\sim 30 \%$ of all inhibitory cells may belong to neurogliaform cell family in the hippocampus (Bezaire and Soltesz, 2013). Thus, the LA and BA, where we estimated $14 \%-15 \%$ of GABAergic cells to be neurogliaform cells, take up an intermediate position between these two cortical structures. Our observation that Cre recombinase under the control of NPY is expressed in a portion of $\mathrm{PV}^{+}$basket and axo-axonic cells in the two amygdalar nuclei examined is novel, but not surprising, as in the hippocampus NPY immunoreactivity has been reported in some $\mathrm{PV}^{+}$interneurons (Klausberger et al., 2004), whereas many $\mathrm{SST}^{+}$GABAergic cells express NPY in cortical regions (He et al., 2016; Lim et al., 2018). 
Adding up the fractions of each GABAergic cell type resulted in a sum, which is close to the ratios of GABAergic cells obtained by unbiased stereological analysis. This notion strongly suggests that the vast majority of GABAergic cells in the LA and BA belong to the seven cardinal inhibitory cell categories examined in this study. In addition to these GABAergic cells typical for cortical structures, other inhibitory cell types do exist in the BLA, such as those expressing muscarinic acetylcholine receptor Type 2 (M2), but they do not provide a large number of GABAergic cells (McDonald and Mascagni, 2011).

Our present study in mice determined the number of GABAergic and non-GABAergic neurons in the LA and BA as well as provided a realistic estimate for the proportions of distinct inhibitory cell types. These results will pave the ground for future studies, specifically for those aiming to reveal the changes in amygdalar inhibitory circuits in different models of neuropsychiatric diseases, including anxiety, autism spectrum disorder, and schizophrenia. The significance of these investigations is highlighted by the fact that hyperexcitability in the amygdala, arising from the imbalance between excitation and inhibition, typifies many pathologic brain states in humans (Rosen and Schulkin, 1998; Rosenkranz et al., 2010; Prager et al., 2016; Sharp, 2017; Takarae and Sweeney, 2017).

\section{References}

Acsády L, Gorcs TJ, Freund TF (1996) Different populations of vasoactive intestinal polypeptide- immunoreactive interneurons are specialized to control pyramidal cells or interneurons in the hippocampus. Neuroscience 73:317-334.

Andrási T, Veres JM, Rovira-Esteban L, Kozma R, Vikór A, Gregori E, Hájos N (2017) Differential excitatory control of 2 parallel basket cell networks in amygdala microcircuits. PLoS Biol 15:e2001421.

Armstrong C, Krook-Magnuson E, Soltesz I (2012) Neurogliaform and ivy cells: a major family of nNOS expressing GABAergic neurons. Front Neural Circuits 6:23.

Beaulieu C, Kisvarday Z, Somogyi P, Cynader M, Cowey A (1992) Quantitative distribution of GABA-immunopositive and -immunonegative neurons and synapses in the monkey striate cortex (area 17). Cereb Cortex 2:295-309.

Bezaire MJ, Soltesz I (2013) Quantitative assessment of CA1 local circuits: knowledge base for interneuron-pyramidal cell connectivity. Hippocampus 23:751-785.

Bienvenu TC, Busti D, Magill PJ, Ferraguti F, Capogna M (2012) Cell-typespecific recruitment of amygdala interneurons to hippocampal theta rhythm and noxious stimuli in vivo. Neuron 74:1059-1074.

Chareyron LJ, Banta Lavenex P, Amaral DG, Lavenex P (2011) Stereological analysis of the rat and monkey amygdala. J Comp Neurol 519:3218-3239.

Freund TF, Katona I (2007) Perisomatic inhibition. Neuron 56:33-42.

Fuentealba P, Klausberger T, Karayannis T, Suen WY, Huck J, Tomioka R, Rockland K, Capogna M, Studer M, Morales M, Somogyi P (2010) Expression of COUP-TFII nuclear receptor in restricted GABAergic neuronal populations in the adult rat hippocampus. J Neurosci 30:15951609.

Gabbott PL, Somogyi P (1986) Quantitative distribution of GABA-immunoreactive neurons in the visual cortex (area 17) of the cat. Exp Brain Res 61:323-331.

Gothard KM (2020) Multidimensional processing in the amygdala. Nat Rev Neurosci 21:565-575.

Gulyas AI, Hajos N, Freund TF (1996) Interneurons containing calretinin are specialized to control other interneurons in the rat hippocampus. J Neurosci 16:3397-3411.

Gulyas AI, Hajos N, Katona I, Freund TF (2003) Interneurons are the local targets of hippocampal inhibitory cells which project to the medial septum. Eur J Neurosci 17:1861-1872.

Hájos N, Acsády L, Freund TF (1996) Target selectivity and neurochemical characteristics of VIP- immunoreactive interneurons in the rat dentate gyrus. Eur J Neurosci 8:1415-1431.
Harris KD, Shepherd GM (2015) The neocortical circuit: themes and variations. Nat Neurosci 18:170-181.

He M, Tucciarone J, Lee S, Nigro MJ, Kim Y, Levine JM, Kelly SM, Krugikov I, Wu P, Chen Y, Gong L, Hou Y, Osten P, Rudy B, Huang ZJ (2016) Strategies and tools for combinatorial targeting of GABAergic neurons in mouse cerebral cortex. Neuron 91:1228-1243.

Huang ZJ, Paul A (2019) The diversity of GABAergic neurons and neural communication elements. Nat Rev Neurosci 20:563-572.

Janak PH, Tye KM (2015) From circuits to behaviour in the amygdala. Nature 517:284-292.

Katona I, Acsady L, Freund TF (1999) Postsynaptic targets of somatostatinimmunoreactive interneurons in the rat hippocampus. Neuroscience 88:37-55.

Katsumaru H, Kosaka T, Heizmann CW, Hama K (1988) Immunocytochemical study of GABAergic neurons containing the calcium-binding protein parvalbumin in the rat hippocampus. Exp Brain Res 72:347-362.

Kawaguchi Y, Kubota Y (1996) Physiological and morphological identification of somatostatin- or vasoactive intestinal polypeptide-containing cells among GABAergic cell subtypes in rat frontal cortex. J Neurosci 16:2701-2715

Kepecs A, Fishell G (2014) Interneuron cell types are fit to function. Nature 505:318-326.

Kim Y, Yang GR, Pradhan K, Venkataraju KU, Bota M, Garcia Del Molino LC, Fitzgerald G, Ram K, He M, Levine JM, Mitra P, Huang ZJ, Wang XJ, Osten P (2017) Brain-wide maps reveal stereotyped cell-type-based cortical architecture and subcortical sexual dimorphism. Cell 171:456469.e422.

Klausberger T, Marton LF, Baude A, Roberts JD, Magill PJ, Somogyi P (2004) Spike timing of dendrite-targeting bistratified cells during hippocampal network oscillations in vivo. Nat Neurosci 7:41-47.

Krabbe S, Paradiso E, d'Aquin S, Bitterman Y, Courtin J, Xu C, Yonehara K, Markovic M, Muller C, Eichlisberger T, Grundemann J, Ferraguti F, Luthi A (2019) Adaptive disinhibitory gating by VIP interneurons permits associative learning. Nat Neurosci 22:1834-1843.

Lim L, Mi D, Llorca A, Marin O (2018) Development and functional diversification of cortical interneurons. Neuron 100:294-313.

Manassero E, Renna A, Milano L, Sacchetti B (2018) Lateral and basal amygdala account for opposite behavioral responses during the long-term expression of fearful memories. Sci Rep 8:518.

Mańko M, Bienvenu TC, Dalezios Y, Capogna M (2012) Neurogliaform cells of amygdala: a source of slow phasic inhibition in the basolateral complex. J Physiol 590:5611-5627.

Mate Z, Poles MZ, Szabo G, Bagyanszki M, Talapka P, Fekete E, Bodi N (2013) Spatiotemporal expression pattern of DsRedT3/CCK gene construct during postnatal development of myenteric plexus in transgenic mice. Cell Tissue Res 352:199-206.

McDonald AJ (1985) Immunohistochemical identification of gamma-aminobutyric acid-containing neurons in the rat basolateral amygdala. Neurosci Lett 53:203-207.

McDonald AJ (1992) Projection neurons of the basolateral amygdala: a correlative Golgi and retrograde tract tracing study. Brain Res Bull 28:179185.

McDonald AJ (1996) Glutamate and aspartate immunoreactive neurons of the rat basolateral amygdala: colocalization of excitatory amino acids and projections to the limbic circuit. J Comp Neurol 365:367-379.

McDonald AJ, Augustine JR (1993) Localization of GABA-like immunoreactivity in the monkey amygdala. Neuroscience 52:281-294.

McDonald AJ, Betette RL (2001) Parvalbumin-containing neurons in the rat basolateral amygdala: morphology and co-localization of Calbindin-D (28k). Neuroscience 102:413-425.

McDonald AJ, Mascagni F (2001) Colocalization of calcium-binding proteins and GABA in neurons of the rat basolateral amygdala. Neuroscience 105:681-693.

McDonald AJ, Mascagni F (2011) Neuronal localization of M2 muscarinic receptor immunoreactivity in the rat amygdala. Neuroscience 196:49-65.

McDonald AJ, Zaric V (2015) GABAergic somatostatin-immunoreactive neurons in the amygdala project to the entorhinal cortex. Neuroscience 290:227-242.

McDonald AJ, Mascagni F, Zaric V (2012) Subpopulations of somatostatinimmunoreactive non-pyramidal neurons in the amygdala and adjacent external capsule project to the basal forebrain: evidence for the existence 
of GABAergic projection neurons in the cortical nuclei and basolateral nuclear complex. Front Neural Circuits 6:46.

Miyoshi G, Fishell G (2011) GABAergic interneuron lineages selectively sort into specific cortical layers during early postnatal development. Cereb Cortex 21:845-852.

Muller JF, Mascagni F, McDonald AJ (2006) Pyramidal cells of the rat basolateral amygdala: synaptology and innervation by parvalbumin-immunoreactive interneurons. J Comp Neurol 494:635-650.

Muller JF, Mascagni F, McDonald AJ (2007) Postsynaptic targets of somatostatin-containing interneurons in the rat basolateral amygdala. J Comp Neurol 500:513-529.

O'Leary TP, Sullivan KE, Wang L, Clements J, Lemire AL, Cembrowski MS (2020) Extensive and spatially variable within-cell-type heterogeneity across the basolateral amygdala. Elife 9:e59003.

Paré D, Smith Y (1998) Intrinsic circuitry of the amygdaloid complex: common principles of organization in rats and cats. Trends Neurosci 21:240241.

Paul A, Crow M, Raudales R, He M, Gillis J, Huang ZJ (2017) Transcriptional architecture of synaptic communication delineates GABAergic neuron identity. Cell 171:522-539.e520.

Pelkey KA, Chittajallu R, Craig MT, Tricoire L, Wester JC, McBain CJ (2017) Hippocampal GABAergic inhibitory interneurons. Physiol Rev 97:16191747.

Perrenoud Q, Rossier J, Geoffroy H, Vitalis T, Gallopin T (2013) Diversity of GABAergic interneurons in layer VIa and VIb of mouse barrel cortex. Cereb Cortex 23:423-441.

Phelps EA, LeDoux JE (2005) Contributions of the amygdala to emotion processing: from animal models to human behavior. Neuron 48:175-187.

Phelps EA, Lempert KM, Sokol-Hessner P (2014) Emotion and decision making: multiple modulatory neural circuits. Annu Rev Neurosci 37:263-287.

Pitkanen A, Savander V, LeDoux JE (1997) Organization of intra-amygdaloid circuitries in the rat: an emerging framework for understanding functions of the amygdala. Trends Neurosci 20:517-523.

Pitkanen A, Savander M, Nurminen N, Ylinen A (2003) Intrinsic synaptic circuitry of the amygdala. Ann NY Acad Sci 985:34-49.

Polepalli JS, Gooch H, Sah P (2020) Diversity of interneurons in the lateral and basal amygdala. NPJ Sci Learn 5:10.

Prager EM, Bergstrom HC, Wynn GH, Braga MF (2016) The basolateral amygdala gamma-aminobutyric acidergic system in health and disease. J Neurosci Res 94:548-567.

Ren JQ, Aika Y, Heizmann CW, Kosaka T (1992) Quantitative analysis of neurons and glial cells in the rat somatosensory cortex, with special reference to GABAergic neurons and parvalbumin-containing neurons. Exp Brain Res 92:1-14.

Rhomberg T, Rovira-Esteban L, Vikór A, Paradiso E, Kremser C, Nagy-Pál P, Papp OI, Tasan R, Erdélyi F, Szabó G, Ferraguti F, Hájos N (2018) Vasoactive intestinal polypeptide-immunoreactive interneurons within circuits of the mouse basolateral amygdala. J Neurosci 38:6983-7003.

Rosen JB, Schulkin J (1998) From normal fear to pathological anxiety. Psychol Rev 105:325-350.

Rosenkranz JA, Venheim ER, Padival M (2010) Chronic stress causes amygdala hyperexcitability in rodents. Biol Psychiatry 67:1128-1136.

Rovira-Esteban L, Gunduz-Cinar O, Bukalo O, Limoges A, Brockway E, Muller K, Fenno LE, Kim YS, Ramakrishnan C, Andrási T, Deisseroth K, Holmes A, Hájos N (2019) Excitation of diverse classes of cholecystokinin interneurons in the basolateral amygdala facilitates fear extinction. eNeuro 6:ENEURO.0220-19.2019.

Schmitz C, Hof PR (2000) Recommendations for straightforward and rigorous methods of counting neurons based on a computer simulation approach. J Chem Neuroanat 20:93-114.
Schumann CM, Amaral DG (2005) Stereological estimation of the number of neurons in the human amygdaloid complex. J Comp Neurol 491:320329.

Sharp BM (2017) Basolateral amygdala and stress-induced hyperexcitability affect motivated behaviors and addiction. Transl Psychiatry 7:e1194.

Sik A, Ylinen A, Penttonen M, Buzsaki G (1994) Inhibitory CA1-CA3-hilar region feedback in the hippocampus. Science 265:1722-1724.

Smith Y, Paré D (1994) Intra-amygdaloid projections of the lateral nucleus in the cat: PHA-L anterograde labeling combined with postembedding GABA and glutamate immunocytochemistry. J Comp Neurol 342:232248.

Smith Y, Paré JF, Paré D (1998) Cat intraamygdaloid inhibitory network: ultrastructural organization of parvalbumin-immunoreactive elements. J Comp Neurol 391:164-179.

Somogyi P (1977) A specific 'axo-axonal' interneuron in the visual cortex of the rat. Brain Res 136:345-350.

Takarae Y, Sweeney J (2017) Neural hyperexcitability in autism spectrum disorders. Brain Sci 7:129.

Tamas G, Lorincz A, Simon A, Szabadics J (2003) Identified sources and targets of slow inhibition in the neocortex. Science 299:1902-1905.

Tricoire L, Pelkey KA, Daw MI, Sousa VH, Miyoshi G, Jeffries B, Cauli B, Fishell G, McBain CJ (2010) Common origins of hippocampal ivy and nitric oxide synthase expressing neurogliaform cells. J Neurosci 30:21652176.

Vereczki VK, Veres JM, Muller K, Nagy GA, Racz B, Barsy B, Hajos N (2016) Synaptic organization of perisomatic GABAergic inputs onto the principal cells of the mouse basolateral amygdala. Front Neuroanat 10:20.

Veres JM, Nagy GA, Vereczki VK, Andrási T, Hajos N (2014) Strategically positioned inhibitory synapses of axo-axonic cells potently control principal neuron spiking in the basolateral amygdala. J Neurosci 34:1619416206.

Veres JM, Nagy GA, Hajos N (2017) Perisomatic GABAergic synapses of basket cells effectively control principal neuron activity in amygdala networks. Elife 6:e202721.

Wang X, Tucciarone J, Jiang S, Yin F, Wang BS, Wang D, Jia Y, Jia X, Li Y, Yang T, Xu Z, Akram MA, Wang Y, Zeng S, Ascoli GA, Mitra P, Gong H, Luo Q, Huang ZJ (2019) Genetic single neuron anatomy reveals fine granularity of cortical axo-axonic cells. Cell Rep 26:3145-3159.e3145.

Wang Y, Toledo-Rodriguez M, Gupta A, Wu C, Silberberg G, Luo J, Markram H (2004) Anatomical, physiological and molecular properties of Martinotti cells in the somatosensory cortex of the juvenile rat. J Physiol 561:65-90.

Watson RE Jr, Wiegand SJ, Clough RW, Hoffman GE (1986) Use of cryoprotectant to maintain long-term peptide immunoreactivity and tissue morphology. Peptides 7:155-159.

West MJ, Slomianka L, Gundersen HJ (1991) Unbiased stereological estimation of the total number of neurons in the subdivisions of the rat hippocampus using the optical fractionator. Anat Rec 231:482-497.

Wolff SB, Grundemann J, Tovote P, Krabbe S, Jacobson GA, Muller C, Herry C, Ehrlich I, Friedrich RW, Letzkus JJ, Luthi A (2014) Amygdala interneuron subtypes control fear learning through disinhibition. Nature 509:453-458.

Xu X, Roby KD, Callaway EM (2010) Immunochemical characterization of inhibitory mouse cortical neurons: three chemically distinct classes of inhibitory cells. J Comp Neurol 518:389-404.

Yamamoto R, Ahmed N, Ito T, Gungor NZ, Paré D (2018) Optogenetic study of anterior BNST and basomedial amygdala projections to the ventromedial hypothalamus. eNeuro 5:ENEURO.0204-18.2018. 